\title{
A 100-Year Review: Yogurt and other cultured dairy products ${ }^{1}$
}

\author{
Kayanush J. Aryana² and Douglas W. Olson \\ School of Nutrition and Food Sciences, Louisiana State University Agricultural Center, Baton Rouge 70803
}

\begin{abstract}
The history of the last 100 years of the science and technology of yogurt, sour cream, cultured butter, cultured buttermilk, kefir, and acidophilus milk has been one of continuous development and improvement. Yogurt leads the cultured dairy product category in terms of volume of production in the United States and recent research activity. Legal definitions of yogurt, sour cream and acidified sour cream, and cultured milk, including cultured buttermilk, are presented in the United States Code of Federal Regulations and summarized here. A tremendous amount of research has been done on traditional and novel ingredients, starter cultures and probiotics, mix processing, packaging, chemical aspects, physical and sensory properties, microstructure, specialized products, composition, quality and safety of yogurt and various manufacturing methods, addition of flavorings, viscosity measurements, and probiotic use for sour cream. Over time, there have arisen alternative manufacturing methods, flavor problems, addition of flavorings, and use of probiotics for cultured buttermilk. Many health benefits are provided by yogurt and other cultured dairy products. One hundred years of testing and development have led to wider uses of cultured dairy products and new processing methods for enhanced shelf life and safety. Future research directions will likely include investigating the effects of probiotic dairy products on gut microbiota and overall health.
\end{abstract}

Key words: cultured dairy products, yogurt, food safety, starter culture and probiotic, 100-year review

\section{INTRODUCTION}

Various cultured dairy products are formed by the conversion of lactose in milk to lactic acid by the use of starter cultures. Starter cultures have been used in the sense of inoculating fresh milk with small quantities of

Received April 3, 2017.

Accepted August 1, 2017.

${ }^{1}$ This review is part of a special issue of the Journal of Dairy Science commissioned to celebrate 100 years of publishing (1917-2017).

${ }^{2}$ Corresponding author: karyana@agcenter.lsu.edu sour milk long before anything about bacteriology was known. Consumption of various fermented milk products by people in different regions of the world living under primitive sanitary conditions, especially in hot climates, was desirable because their high acidity kept these products safe by destroying pathogenic organisms (Nicholls and Nimalasuriya, 1939).

A critically important early advancement in bacteriology was the first observation of bacteria by Antonie van Leeuwenhoek in about 1675 (Orla-Jensen, 1921). Swithinbank and Newman (1903) reported that Andry, as early as 1701, noticed that living organisms are present in sour milk.

Lactic acid was first studied in 1780 by Carl Wilhelm Scheele (Van Slyke and Hart, 1904). Louis Pasteur declared that lactic acid could be formed from sugar fermentation by yeast (probably actually lactic acid bacteria) in 1857, as described and referenced by Manchester (2007). Whether credit should be given to Louis Pasteur or to Pierre Jacques Antoine Béchamp (for his work on inversion of sucrose in 1855) for the first demonstration of fermentation by living organisms was a subject of controversy between these 2 scientists (Manchester, 2007). Joseph Lister, known for his work in showing the critical importance of antiseptic technique during surgery, also studied milk souring by lactic fermentation and believed that milk sugar is converted into lactic acid (Lister, 1878). The older view was that casein was the ferment.

During the 1800s, it was debated whether true fermentation of organic liquids was caused by organisms that they contain. Lister, like Pasteur, believed that organisms caused fermentation but acknowledged that some distinguished physiologists and pathologists at that time believed that fermentation such as putrefaction was not necessarily caused by bacteria (Lister, 1878). Lister (1873) first isolated the organism that he called Bacterium lactis, later renamed Streptococcus lactis (Orla-Jensen, 1919), and now referred to as Lactococcus lactis ssp. lactis (Schleifer et al., 1985); this organism converts lactose into lactic acid. Lister was not sure if this was the only bacterium that could undergo lactic acid fermentation.

A history during the 1800 s and early 1900 s of the use of butter starters for souring that can occur under 
the right conditions was provided by Knudsen (1931). The introduction of the thermometer for use in cream ripening by Segelcke in 1860 and improved recordkeeping for use of definite quantities of starter for definite quantities of cream improved the control of cream souring (Knudsen, 1931). Many other advancements in cultures, ingredients, processing, and packaging were developed over time to improve cultured dairy products. Today, cultured dairy products are fermented with lactic acid bacteria, including species of Lactobacillus, Streptococcus, Lactococcus, and Leuconostoc (Appendix Table A1). Yeasts are also used in manufacturing kefir and koumiss.

Some of the more common and well-known cultured dairy products include yogurt, sour cream and dips, cultured buttermilk, acidophilus milk, and kefir. A list of many other lesser-known cultured dairy foods available in specific countries or regions can be found in Chandan (2006) and at https://en.wikipedia.org/ wiki/Fermented_milk_products. Consumers generally have a positive perception of yogurt. As a result, annual per capita yogurt consumption increased from $0.1 \mathrm{~kg}$ in 1970 to $1.2 \mathrm{~kg}$ in 1977 in the United States (Tamime and Deeth, 1980), and production of yogurt has increased from 982.6 million pounds in 1990 to about 4,742.1 million pounds in 2015 (International Dairy Foods Association, 2017) in the United States. Sour cream production has increased from 935.4 million pounds in 2003 to about 1,316.5 million pounds in 2015, and buttermilk sales have decreased from 1,140 million pounds in 1960 to about 513 million pounds in 2015 in the United States (International Dairy Foods Association, 2017). Because of the recent economic importance of yogurt as well as the large number of published articles, the emphasis of this review paper will be on yogurt (Appendix Table A1), with less coverage on other cultured dairy products, including sour cream, cultured butter, cultured buttermilk, kefir, acidophilus milk, and the probiotic dairy beverage Yakult (Yakult Honsha Co., Tokyo, Japan).

\section{YOGURT}

\section{History and Legal Description of Yogurt}

For an early method of yogurt manufacturing, Heineman (1921) described the manufacture of yogurt as boiling milk in clean earthenware vessels over a slow fire to reduce the volume of milk from about one-fourth to more than one-half (so that the final volume is between less than $50 \%$ to $75 \%$ of the original volume), cooling to 45 to $50^{\circ} \mathrm{C}$, adding a small amount of product from a previous lot, wrapping the vessels containing this mixture in skins and cloths to maintain a uniform tem- perature for 10 to $12 \mathrm{~h}$ before being ready for consumption. For modern methods of yogurt manufacturing, yogurt mix with an appropriate fat content (typically $<0.5,1$, or $3.25 \%$ ) and total solids content (typically 12 to $15 \%$ and adjusted by adding nonfat dry milk) is homogenized, pasteurized [typically at 90 to $95^{\circ} \mathrm{C}$ for close to a minute to a few minutes (HTST) or at about $85^{\circ} \mathrm{C}$ for $30 \mathrm{~min}$ (vat)], and cooled to 40 to $45^{\circ} \mathrm{C}$ before pumping into a vat (often cylindrical-shaped on the top and cone-shaped on the bottom). The mix is then inoculated with Streptococcus salivarius ssp. thermophilus (traditionally and hereafter referred to as Streptococcus thermophilus) and Lactobacillus delbrueckii ssp. bulgaricus (traditionally and hereafter referred to as Lactobacillus bulgaricus). The inoculated mix may then be immediately pumped to a yogurt filler for filling into cups, with or without fruit puree already present in the bottom of the cup, and the cups are then sealed. The filled and sealed cups are then transferred to a warm room for incubation. When the yogurt reaches the appropriate $\mathrm{pH}$ (typically about 4.5 ), the yogurt cups are transferred to refrigerated storage (cup or sundae-style yogurt). Instead of immediate pumping to a yogurt filler, the inoculated mix may be allowed to incubate within the vat until the $\mathrm{pH}$ reaches the appropriate value, typically about 4.5 . The inoculated mix is then stirred and cooled to about $20^{\circ} \mathrm{C}$ before pumping to a fruit feeder for adding fruit (for fruit-flavored yogurt) and then to a yogurt filler for filling into cups and then cup sealing. The cups are then transferred to refrigerated storage. More details of these procedures are provided by Kosikowski and Mistry (1997).

Yogurt has evolved over time. The industrial production of yogurt incorporating microorganisms was started by Isaac Carasso in 1919 (http://corporate.danone.co .uk/en/discover/our-businesses/fresh-dairy-products/ brand-detail/?tx_bidanonesitemarques_pi1\%5Buid $\% 5 \mathrm{D}=324 \& \mathrm{cHash}=0 \mathrm{c} 2732 \mathrm{c} 382 \mathrm{f} 800736405 \mathrm{ab} 84 \mathrm{df} 99142$ f). During the 1920s and 1930s, yogurt milk was described as having poor flavor because of its high acidity (Winkler, 1929; Nordsiek, 1938). Before the 1960s, yogurt was only found in a few grocery or health food stores (Kroger, 1975). Today, many forms of yogurt can be found including plain yogurt, fruit flavored yogurt (including fruit-on-the-bottom and blended forms), whipped yogurt, granola-topped yogurt, drinkable yogurt, frozen yogurt, and Greek yogurt with varying fat contents (regular, low fat, and nonfat). The order for the US sales of spoonable yogurt flavors includes strawberry, blueberry, vanilla, peach, plain, raspberry, honey, banana and strawberry, black cherry, berry, pineapple, cherry, key lime, lemon, and banana (Cassell, 2014). Earlier in the decade, sales of Greek yogurt grew rapidly. Future trends for yogurt include sugar reduction 
(Chollet et al., 2013) and predicted rapid sales growth for drinkable yogurt, as reported by Conick (2016), Shoup (2016), and Kennedy (2016); yogurt with savory flavors (Kennedy, 2016); and whole milk yogurt (Kennedy, 2016).

A legal description of yogurt, lowfat yogurt, and nonfat yogurt is given in the US Code of Federal Regulations in 21CFR131.200 (CFR, 2017a), 21CFR131.203 (CFR, 2017b), and 21CFR131.206 (CFR, 2017c), respectively. Yogurt, lowfat yogurt, and nonfat yogurt contain at least $3.25 \%$ milkfat, between $0.5 \%$ and $2 \%$ milkfat, and less than $0.5 \%$ milkfat, respectively, and each of these products contain at least $8.25 \%$ milk solids-not-fat before addition of bulky flavors. Optional dairy ingredients, including cream, milk, partially skim milk, or skim milk, used alone or in combination, are cultured with Lactobacillus bulgaricus and Streptococcus thermophilus and result in a titratable acidity of at least $0.9 \%$ expressed as lactic acid. Pasteurization or ultra-pasteurization must be performed before adding the cultures. These yogurt products may contain certain other dairy-based ingredients, nutritive carbohydrate sweeteners, flavoring ingredients, color additives, stabilizers, and vitamins A and D. Also, these yogurt products may be heat treated to kill viable microorganisms after culturing to extend product shelf life.

\section{Ingredients in Yogurt}

Some of the added dairy ingredients that increase the milk solids-not-fat content of yogurt mixes have included skim or whole milk powders, milk protein concentrates, condensed milk, buttermilk powder, whey powder, whey protein concentrates, microparticulated whey protein, and caseinates (sodium, calcium, or sodium-calcium). Schulz (1949) stated that addition of condensed skim milk to milk for making yogurt improves yogurt consistency. Addition of milk powder to milk has been used for many years to produce a thicker and firmer yogurt (Pette and Lolkema, 1951). Todoric and Savadinovic (1973) stated that up to $0.3 \%$ dried whey can replace dried skim milk in manufacturing yogurt. Horton et al. (1972) mentioned that liquid cottage cheese whey protein concentrates could be used in yogurt production. Modler et al. (1983) added caseinate, milk protein concentrate, skim milk powder, and whey protein concentrates (prepared by ultrafiltration, ion exchange, or electrodialysis/lactose crystallization) to yogurt at concentrations ranging from 0.5 to $1.5 \%$ and found that gel firmness tended to be higher and syneresis (defined as liquid whey phase on the top resulting from gel shrinkage) lower with use of the caseinbased additives and with the highest incorporation rates. Bong and Moraru (2014) developed a procedure for manufacturing Greek-style yogurt in which micellar casein concentrate was used to increase the protein content of the milk for making yogurt. Trachoo and Mistry (1998) added ultrafiltered sweet buttermilk and sweet buttermilk powder to fortify skim milk in the manufacture of nonfat and low fat yogurts. Saffon et al. (2013) reported that replacing powdered skim milk with heat-denatured aggregates of mixtures of buttermilk concentrate and whey protein concentrate in set-type yogurt modified the textural properties of the resulting yogurt.

Yogurt may or may not contain fat. The fat content of yogurt is normally adjusted by varying the amount of added cream, milk, partially skim milk, or skim milk. However, unsalted butter can also be used to increase the yogurt fat content (Chandan et al., 1969). A butterfat-free yogurt in which an unsaturated fat or oil such as corn oil, cottonseed oil, coconut oil, soybean oil, or other similar oils in amounts of about 1.5 to $6.4 \%$ are added has been patented (Metzger, 1962b). Historical trends of varying yogurt fat contents are discussed in the various types of yogurt section.

Today, most yogurts, other than plain yogurt, are sweetened, usually with sugar. Other sweeteners such as honey can be used, but Popa and Ustunol (2011) found that the flavor of yogurt sweetened with sucrose was preferred by panelists over yogurts sweetened with either high-fructose corn syrup or honey. Various highintensity sweeteners can be incorporated into yogurt. The sweeteners fructose, xylitol, sorbitol, cyclamate, and a saccharin and xylitol mixture (use of xylitol in this mixture to cover a disturbing bitter aftertaste from saccharin) could be successfully used in yogurt when added after incubation without markedly deteriorating quality (Hyvönen and Slotte, 1983). A method of making yogurt containing pectin and aspartame was patented by Malone and Miles (1984). Keating and White (1990) reported that yogurts sweetened with either aspartame or sorbitol were usually preferred over yogurts sweetened with other alternative sweeteners (calcium saccharin, sodium saccharin, fructose, sucrose plus monoammonium glycyrrhizinate, fructose plus monoammonium glycyrrhizinate, acesulfame$\mathrm{K}$, and dihydrochalcone) but not as desirable as the sucrose-sweetened yogurt control. When matching the sweetness equivalence of strawberry yogurt containing $11.5 \%$ (wt/wt) sucrose with addition of high-intensity sweeteners to yogurt, Reis et al. (2011) found that more aspartame than sucralose was required. Narayanan et al. (2014) found that levels of 0.7 to $5.5 \%$ (wt/wt) of various commercial stevia sweeteners were appropriate for sweetening naturally flavored vanilla low-fat yogurt.

Stabilizers are often added to yogurt. Hall (1975) has provided recommendations for usage of stabilizer 
depending upon preferences in the type of yogurt to be produced. Common stabilizers for use in yogurt and yogurt drinks include modified starch, gelatin, agar, pectin, locust bean gum, xanthan gum, carrageenan, and carboxymethyl cellulose, used either alone or in combination, depending upon the type of stabilizer (Chandan and O'Rell, 2006).

Fruit is commonly added to yogurt and has been since 1933 (as described at http://ekonomika.idnes.cz/ prvni-ovocny-jogurt-se-narodil-u-vltavy-fdi-/test.aspx $\left.? c=A 020723 \_103620 \_t e s t \_j a n\right)$. Davis (1973) stated that the incorporation of real fruit into yogurt led to soaring yogurt sales in Britain. Some of the more common types of fruit added to yogurt include strawberry, blueberry, peach, raspberry, cherry, orange, lemon, and pineapple (Saal and Krebs, 1975); many other fruit and fruit flavors that have been used are listed in Robinson and Tamime (1975).

Many nutritional and functional ingredients have been added to yogurt. Because yogurts are not typically vitamin fortified, studies have reported the addition of vitamins (either with or without other added ingredients) including vitamin C (Maxa, 1949; patented by Metzger, 1962a), vitamin $\mathrm{B}_{12}$ (by addition of Propionibacterium shermanii or $2 \%$ yeast extract; Karlin, 1961), vitamins A and C (Ilic and Ashoor, 1988), folic acid (Aryana, 2003), vitamin $\mathrm{D}_{3}$ (Kazmi et al., 2007), and some heart-healthy nutrients (thiamine, riboflavin, niacin, folic acid, manganese, magnesium, and fiber; Cueva and Aryana, 2008). Other examples of adding beneficial ingredients to yogurt during manufacturing include calcium (Tchilinguirian, 1960), nanopowdered eggshells (Mijan et al., 2014), iron (Hekmat and McMahon, 1997), 7 different types of minerals (iron, magnesium, zinc, manganese, molybdenum, chromium, and selenium; Achanta et al., 2007), vegetables (cucumber salad, tomato salad, beet salad, and garden salad; Anonymous, 1976), nuts (walnuts, hazelnuts, almonds, and pistachios; Ozturkoglu-Budak et al., 2016), spice oleoresins (cardamom, nutmeg, and cinnamon; Illupapalayam et al., 2014), fish oil (Estrada et al., 2011; reviewed by Olson and Aryana, 2017), fiber (patented by Reddy, 1989, and Hoyda et al., 1990), oat fiber (Fernández-García et al., 1998), inulin (Robinson, 1995), resistant starch (Anonymous, 1997), lutein (Aryana et al., 2006), plant sterols (Volpe et al., 2001), and green tea and green coffee powders (Dönmez et al., 2017).

\section{Yogurt Cultures and Added Probiotics}

Although current standard procedures and regulations call for the addition of both Streptococcus thermophilus and Lactobacillus bulgaricus as the starter culture to be used in the production of yogurt (or possibly yogurt-like products) because of their symbiotic relationship (as will be discussed in more detail below), other cultures or combinations have been suggested over time. Rosell (1933) described 3 types of bacteria in preparing yogurt milk: "thermo- or plocamo-bacterium yoghourtii (Jensen), the Bacterium bulgaricum (Grigoroff) and the Streptococcus lacticus thermophilus (Jensen, Weigman, and Henneberg)." Davis (1973) used the phrase "a culture of L. bulgaricus and other lactic acid bacteria in milk or concentrated milk" to describe traditional yogurt. Adjunct cultures and probiotics can also be added to yogurt.

Orla-Jensen (1919) described Streptococcus thermophilus. It is the most frequently occurring Streptococcus in milk pasteurized at low temperatures. The most rapid growth occurs at 40 to $45^{\circ} \mathrm{C}$, and the best growth is in milk. Streptococcus thermophilus forms longer chains at $45^{\circ} \mathrm{C}$ than at $30^{\circ} \mathrm{C}$. Thick capsules, or even slime (probably exopolysaccharides and discussed in more detail below), can be formed by several strains. It does not markedly dissolve casein and it slightly ferments maltose and mannose but not salicin (OrlaJensen, 1919). Radke-Mitchell and Sandine (1986) found that temperature for optimal acid production by $S$. thermophilus ranged from about 2 to $8^{\circ} \mathrm{C}$ higher than the temperature for its optimal growth. Streptococcus thermophilus was later reclassified as Streptococcus salivarius ssp. thermophilus (Farrow and Collins, 1984).

Grigoroff described L. bulgaricus in 1905 as documented and referenced by Kulp and Rettger (1924). Orla-Jensen (1919) called the bacteria isolated from Bulgarian yogurt Thermobacterium bulgaricum. Lactobacillus bulgaricus was later reclassified as Lactobacillus delbrueckii ssp. bulgaricus (Weiss et al., 1983).

Complete genomic sequences of various strains of $S$. thermophilus and L. bulgaricus have been published. Bolotin et al. (2004) reported the genome sequences of $S$. thermophilus CNRZ1066 and LMG13811 isolated from yogurt and found that these strains contain a single circular chromosome of about 1,800,000 bp with $39 \%$ $\mathrm{G}+\mathrm{C}$ content for about 1,900 coding sequences. As of August 2015, the genomes of 17 S. thermophilus strains are publicly available (Vendramin et al., 2017). van de Guchte et al. (2006) reported the genome sequence of the L. bulgaricus ATCC11842 that Orla-Jensen originally isolated from Bulgarian yogurt in 1919. This strain contains $1,864,998 \mathrm{bp}$ with an overall $\mathrm{G}+\mathrm{C}$ content of $49.7 \%$. A draft genome sequence of L. bulgaricus LBB. $\mathrm{B} 5$, a strain that originates from homemade Bulgarian yogurt and forms a strong symbiotic relationship with S. thermophilus, was published by Urshev et al. (2016).

Genetic modification of $S$. thermophilus has been performed. Somkuti and Steinberg (1988) genetically 
transformed intact cells of $S$. thermophilus with plasma DNA by electric field pulses. Blomqvist et al. (2010) demonstrated site-directed mutagenesis on $S$. thermophilus LMG 18311 that could allow construction of starter strains that possess novel or improved properties.

Various culture media have been developed or improved over time to isolate and enumerate streptococci and lactobacilli. Heinemann and Hefferan (1909) found that Bacillus bulgaricus (L. bulgaricus) does not grow well on ordinary laboratory media but grows most favorably on milk or a medium containing whey, peptone, and glucose. To overcome the difficulties in preparing the whey and digest media, Kulp (1927) prepared an agar by adding peptone, tomato juice, and water, adjusting the $\mathrm{pH}$ to 7.0, and adding agar and found optimum colony development of various strains of $L$. bulgaricus after incubation in an atmosphere containing $10 \% \mathrm{CO}_{2}$ for $72 \mathrm{~h}$. Davis (1935) found that yeast dextrose litmus milk was the best medium for supporting growth of bacteria important for dairying, including strains of Thermobacteria bulgaricus (L. bulgaricus). McLaughlin (1946) devised trypticase sugar agar to cultivate lactobacilli. Briggs (1953) developed a medium containing tomato juice, Tween 80 (polyoxyethylene sorbitan mono-oleate), and other ingredients that supported growth of a collection of lactobacilli including strains of L. bularicus. An agar developed by Elliker et al. (1956) supports growth of fastidious strains of streptococci and lactobacilli. De Man, Rogosa, and Sharpe (MRS) agar, a commonly used, general nonselective growth medium for lactobacilli, was described by de Man et al. (1960). Terzaghi and Sandine (1975) developed M17 medium and found that both $S$. thermophilus and $L$. bulgaricus grew well in M17, especially with adjustment of $\mathrm{pH}$ to 6.8 before inoculation. Dave and Shah (1996) recommended Streptococcus thermophilus agar for selectively enumerating $S$. thermophilus and either MRS agar adjusted to $\mathrm{pH} 5.2$ or reinforced clostridial agar adjusted to $\mathrm{pH} 5.3$ for selectively enumerating $L$. bulgaricus. Tharmaraj and Shah (2003) described $S$. thermophilus colonies as round and yellowish and 0.1 to $0.5 \mathrm{~mm}$ in diameter when plated on Streptococcus thermophilus agar, and L. bulgaricus colonies as white, cottony, rough, and irregular and $1.0 \mathrm{~mm}$ in diameter when plated on MRS agar adjusted to $\mathrm{pH} 4.58$.

Molecular-based techniques have been developed to identify $S$. thermophilus and L. bulgaricus. Lick and Teuber (1992) synthesized a species-specific DNAoligonucleotide probe allowing rapid identification of $S$. thermophilus using DNA hybridization. Afterward, Lick et al. (1996) developed a primer-specific PCR technique based on the lac $Z$ gene sequence for rapid and accurate identification of S. thermophilus. Both L. bulgaricus and
S. thermophilus can be identified quickly and accurately with PCR using methionine biosynthesis and 16S rRNA genes (Cebeci and Gürakan, 2008).

Traditional production of fermented products used a mother culture. A mother culture is a culture of small volume that is transferred to a larger container or vat of milk for preparing a larger volume of starter for ripening milk or cream in the manufacture of fermented milk products. Starter cultures can be obtained as frozen pellets or in the freeze-dried form. Rogers (1914) was able to prepare $B$. bulgaricus (L. bulgaricus) cultures with high activity by a freezing-vacuum method. Concentrated cultures frozen in liquid nitrogen have been commercially developed for use for manufacturing various types of dairy products including yogurt (Christensen, 1969). The history of the development of dairy cultures is summarized by Wigley (1977) and Jespersen (1977).

A symbiotic relationship between $S$. thermophilus and $L$. bulgaricus has been observed. This symbiotic relationship within yogurt and other cultured dairy products was reported by Orla-Jensen (1921). Pette and Lolkema (1950a) described the relationship between $L$. bulgaricus and $S$. thermophilus as symbiosis and then as antibiosis. Lactobacillus bulgaricus stimulated $S$. thermophilus growth when S. thermophilus was in the logarithmic phase of growth but later, L. bulgaricus inhibited S. thermophilus because of the large amount of lactic acid produced by L. bulgaricus. However, Jankov and Stoyanov (1966) reported that certain strains of $L$. bulgaricus were clearly antagonistic with $S$. thermophilus, and therefore not suitable for yogurt production. They isolated only 6 strains of $L$. bulgaricus out of 442 isolations of lactic acid bacteria from raw milk, and only 2 of these strains were suitable for making yogurt. Also, they reported that the most suitable L. bulgaricus to $S$. thermophilus ratios to result in desirable yogurt were between 2:1 and 1:5 (Jankov and Stoyanov, 1966). A symbiotic relationship between $L$. bulgaricus and $S$. thermophilus was also shown by the higher production of acetaldehyde in milk by a 1:1 mixture of these microorganisms than by either of the microorganisms alone (Hamdan et al., 1971). Although Radke-Mitchell and Sandine (1986) found optimum growth temperatures of 35 to $42^{\circ} \mathrm{C}$ for $S$. thermophilus and 43 to $46^{\circ} \mathrm{C}$ for $L$. bulgaricus, the growth of mixed cultures of $L$. bulgaricus and $S$. thermophilus in milk was not affected by these optimum growth temperatures of the strains grown individually but appeared to be dependent on the concentration or type of stimulatory factors produced by L. bulgaricus. When growing equal volumes of $S$. thermophilus and L. bulgaricus together in milk at 37, 42, and $45^{\circ} \mathrm{C}$, Radke-Mitchell and Sandine (1986) found that $S$. thermophilus usually obtained higher cell 
counts than L. bulgaricus with rod to coccus ratios ranging from 1:2.2 to $1: 8$.

Bacteriophages (viruses that infect bacteria and then replicate within them, leading to bacterial destruction by lysis) have been reported for yogurt cultures. Pette and Kooy (1952) isolated bacteriophages active against $S$. thermophilus in slow-souring yogurt. They also reported that different strains varied in their susceptibility to these bacteriophages. In addition, these phageinfected cultures regained normal acid production, leading to products with normal flavor upon continued cultivation, and becoming insensitive to subsequent bacteriophage attack (Pette and Kooy, 1952). Deane et al. (1953) observed the microstructure of a bacteriophage that attacks $S$. thermophilus that was isolated from Swiss cheese whey and found head sizes of 90 to $95 \mu \mathrm{m}$ in diameter and tail lengths ranging from 225 to $275 \mu \mathrm{m}$. Both Deane et al. (1953) and Stolk (1955) measured the heat resistance of bacteriophage active against $S$. thermophilus and the latter study found that heat treatments of $80^{\circ} \mathrm{C}$ or $85^{\circ} \mathrm{C}$ for $10 \mathrm{~s}$ were necessary to destroy these bacteriophages from yogurt. Mocquot and Hurel (1970) reported that bacteriophage active against $L$. bulgaricus is rare, but Pette did find one, as reported by Humphreys and Plunkett (1969). Peake and Stanley (1978) obtained bacteriophage plaques for a bacteriophage of $L$. bulgaricus isolated from commercial yogurt and showed, by electron microscopy, that this bacteriophage had an approximately 60-nm hexagonal head and an approximately 210-nm tail with a variable number of cross-bar structures.

Starter cultures produce exopolysaccharides, and exopolysaccharides enhance the body of yogurt and provide health benefits to consumers. In 1973, Groux, as reported by Zourari et al. (1992), found that the slime secreted by a strain of $L$. bulgaricus consists primarily of galactose but also contains some glucose, mannose, and arabinose. Lactobacillus bulgaricus has been shown to produce exopolysaccharides that contain galactose, glucose, and rhamnose in an approximately 4:1:1 molar ratio and with a molecular weight of approximately 500,000 (Cerning et al., 1986), and $S$. thermophilus has been shown to produce exopolysaccharides consisting primarily of galactose and glucose with smaller amounts of xylose, arabinose, rhamnose, and mannose (Cerning et al., 1988). The structures and properties of exopolysaccharides produced by various strains of $S$. thermophilus have recently been described by Pachekrepapol et al. (2017). Galesloot and Hassing (1968) found that mixing a high slime-producing L. bulgaricus culture with a commonly used $S$. thermophilus culture during yogurt making led to a stirred yogurt with increased viscosity. Skim milk gels produced by slime-producing strains had decreased susceptibility to syneresis and higher viscosities than skim milk gels produced by non-ropy strains (Schellhaass and Morris, 1985). Exopolysaccharides provide potential health benefits including prebiotic effects, immunostimulatory activity, anti-tumoral activity, and reduced blood cholesterol levels, as described by O'Connor et al. (2005).

The biochemistry, including production of volatile compounds by these starter cultures, has been studied extensively. Pette and Lolkema (1950b) found that acetaldehyde production was linked to the true yogurt aroma. Renz and Puhan (1975) concluded that bitterness in yogurt largely resulted from proteolysis by $L$. bulgaricus during storage. Dan et al. (2017) used solidphase microextraction and gas chromatography-mass spectrometry methods to identify 53,43 , and 32 volatile compounds produced by $S$. thermophilus alone, L. bulgaricus alone, and both species together in fermented milk and confirmed the presence of some important flavor compounds including acetic acid, acetaldehyde, acetoin, 2,3-butanedione, ethanol, and 1-heptanol.

Other cultures can be added to yogurt to improve the flavor. Rašić and Milanović (1966) found that the flavor of yogurt could be improved with the addition of a Streptococcus diacetylactis culture. Lawrence and Perry (1962) reported that adding a flavor-forming strain of a psychrotrophic Leuconostoc could improve the flavor of some fermented milk products, including yogurt.

Addition of unique strains of starter cultures results in novel, value-added products. Anbukkarasi et al. (2014) used galactose-positive strains to produce low-galactose yogurt. Consumption of food products high in galactose is harmful to individuals with galactosemia. Linares et al. (2016) used S. thermophilus APC151 to produce yogurt that contains $\gamma$-aminobutyric acid (GABA) and that has comparable properties of a reference yogurt. $\gamma$-Aminobutyric acid promotes health by its anti-stress, anti-hypertensive, and anti-diabetic properties.

Probiotics are beneficial organisms. Lilly and Stillwell (1965) used the term "probiotics" to describe the production of growth-promoting factors produced by one species of protozoa that assists the growth of another species of protozoa. More recently, probiotics have been defined as "live microorganisms which when administered in adequate amounts confer a health benefit on the host" (FAO/WHO, 2002). The health benefits of a probiotic can be shown by well-designed double-blind, randomized, placebo-controlled trials. Health benefits provided by various probiotic microorganisms have been summarized by Fijan (2014).

Yogurt is often a carrier of probiotics (LourensHattingh and Viljoen, 2001). Lactobacillus acidophilus (described by Moro in 1900, as documented and referenced by Kulp and Rettger, 1924) with or without Bifidobacteria spp. (described by Tissier in 1900, as 
documented and referenced by Kulp and Rettger, 1924) are commonly added to yogurt. Lactobacillus casei DN114001 (L. casei strain CNCM I-1518 or L. casei Immunitas) has been patented (Cayuela et al., 2007) and is used in the probiotic yogurt-type drink DanActive (Actimel; Groupe Danone, Paris, France; https://www .actimel.co.uk/the-story-so-far) that became commercially available in 1994. Bifidobacterium animalis DN173010 is a probiotic used in the yogurt brand Activia (Groupe Danone) that was launched in France in 1987 (https://www.activia.ca/en-us/explore-science/history -activia). Lactobacillus rhamnosus GG (ATCC 53103; also known as Lactobacillus GG) is a probiotic patented as L. acidophilus GG and later reclassified as $L$. rhamnosus GG (Gorbach and Goldin, 1989). Hekmat et al. (2009) reported that L. rhamnosus GR-1 and, to a lesser extent, Lactobacillus reuteri $\mathrm{RC}-14$ were able to survive in yogurt.

\section{Milk and Mix Processing and Yogurt Packaging}

Membrane filtration has been applied to making yogurt. Ultrafiltration of whole milk by a volume reduction of 2 was successfully used to manufacture a high-quality yogurt containing $21 \%$ total solids without the use of nonfat dry milk or homogenization (Chapman et al., 1974). Davies et al. (1977) successfully manufactured yogurt from milk concentrated to 12.5 to $15 \%$ total solids by reverse osmosis. Jepsen (1979) noted that a French factory used reverse osmosis to concentrate skim milk to $13 \%$ total solids at $5^{\circ} \mathrm{C}$ for the manufacture of yogurt.

Various heat treatments of yogurt milk or mixes reduce the manufacturing time and improve some physical properties of the resulting yogurt. Pette and Lolkema (1951) stated that the yogurt curd is improved by milk pasteurization, which is preferably performed at $85^{\circ} \mathrm{C}$ for 5 min because overheating of the milk can weaken the curd. By holding milk for $30 \mathrm{~min}$ at $85^{\circ} \mathrm{C}$ instead of cooling it immediately before souring the milk, Grigorov (1966a) reported that the time for coagulation decreased from 2.43 to $2.01 \mathrm{~h}$, with the $\mathrm{pH}$ of the sour milk at the time of coagulation increasing from 4.70 to 5.16. Grigorov (1966b) recommended a pasteurization temperature of $85^{\circ} \mathrm{C}$ with a holding time of 20 to $30 \mathrm{~min}$ to minimize syneresis in the resulting yogurt, and reported a deterioration of product quality at pasteurization temperatures of 90 and $95^{\circ} \mathrm{C}$ with similar holding times. Yogurt made by vat heating $\left(85^{\circ} \mathrm{C}\right.$ for 10 to $\left.40 \mathrm{~min}\right)$ of the mix was firmer and more viscous than yogurt made by either HTST $\left(98^{\circ} \mathrm{C}\right.$ for 0.5 to $\left.1.87 \mathrm{~min}\right)$ or UHT $\left(140^{\circ} \mathrm{C}\right.$ for 2 to $8 \mathrm{~s}$ ) heating of the mix (Parnell-Clunies et al., 1986). Heating yogurt mixes at $100^{\circ} \mathrm{C}, 110^{\circ} \mathrm{C}$, or $120^{\circ} \mathrm{C}$ for 4 or $16 \mathrm{~s}$ led to yogurts characterized with a firmer gel and increased viscosity compared with yogurt manufactured by heat treatments of the mix at $140^{\circ} \mathrm{C}$ for 4 or $16 \mathrm{~s}$ (Savello and Dargan, 1995). Also, Savello and Dargan (1997) found less syneresis in yogurt manufactured from UF-concentrated skim milk heat treated between $100^{\circ} \mathrm{C}$ and $130^{\circ} \mathrm{C}$ than in yogurt manufactured from UF-concentrated skim milk that was heat treated at $140^{\circ} \mathrm{C}$ or vat heated at $82^{\circ} \mathrm{C}$ for $20 \mathrm{~min}$.

Various pressure treatments (homogenization, microfluidization, and high hydrostatic pressures) have been performed on yogurt mixes and on the finished product. Pette and Lolkema (1951) reported increased curd firmness and prevention of creaming and whey separation in yogurt that was made from pasteurized milk that was homogenized. Schmidt and Bledsoe (1995) found that a yogurt containing $1.5 \%$ fat can be manufactured to have similar physical and sensory properties, except for syneresis and water-holding capacity, to a full-fat (3.5\% fat) yogurt by using homogenization pressures of either 10.344 or $34.48 \mathrm{MPa}$ during manufacture. Ciron et al. (2012) used low-fat milk microfluidized at 50 to $150 \mathrm{MPa}$ to manufacture low-fat yogurt that had creaminess and textural properties resembling full-fat yogurt manufactured with conventional valve homogenization. Harte et al. (2003) manufactured low-fat set yogurt from fortified skim milk subjected to high hydrostatic pressure processing between 300 to 676 $\mathrm{MPa}$ for $5 \mathrm{~min}$ and thermal processing at $85^{\circ} \mathrm{C}$ for 30 min and found that the yogurt manufactured using the 400 to $500 \mathrm{MPa}$ pressure treatments of the fortified skim milk had increased yield stress, increased normal penetration resistance, and increased elastic modulus but less syneresis compared with yogurt manufactured without the high hydrostatic pressure processing. These improved properties of yogurt will allow yogurt to be manufactured with less stabilizers and thickeners (Harte et al., 2003). de Ancos et al. (2000) subjected stirred low-fat yogurts to high hydrostatic pressures (100 to $400 \mathrm{MPa}$ ) for $15 \mathrm{~min}$ at $20^{\circ} \mathrm{C}$ and prevented post-acidification of yogurt during refrigerated storage when using pressures above $200 \mathrm{MPa}$, increased yogurt viscosity after refrigerated storage, reduced counts of viable lactobacilli when using pressures of 300 and 400 $\mathrm{MPa}$, and improved the general acceptability, flavor, and texture using pressures of 200 and $300 \mathrm{MPa}$ compared with the control yogurt.

Many projects dealing with inoculation have described factors affecting counts of $L$. acidophilus during incubation and storage, as low survival of probiotics during storage has been observed. Shah et al. (1995) found $L$. acidophilus counts of $10^{7}$ to $10^{8}$ viable cells/g of yogurt in 3 out of 5 brands and less than $10^{5}$ cells/g in the remaining 2 brands when fresh. Gilliland and Speck (1977) reported low survival of L. acidophilus 
incorporated into yogurt after incubation, and this low survival was explained by production of hydrogen peroxide by L . bulgaricus. Hull et al. (1984) found a decrease of $L$. acidophilus counts by approximately half after $3 \mathrm{wk}$ of storage when adding L. acidophilus culture with the starter culture, but L. acidophilus survival was less than $1 \%$ after $4 \mathrm{~d}$ of $5^{\circ} \mathrm{C}$ storage when added after incubation. Olson and Aryana (2008) found that $L$. acidophilus counts in yogurt could be increased by increasing its inoculation level to a point, but excessively high inoculation of $L$. acidophilus levels lowered counts during storage and adversely affected yogurt quality, including decreased apparent viscosity and sensory scores but increased syneresis compared with yogurts manufactured with lower L. acidophilus inoculation levels.

Yogurt packaging has changed over time. Yogurt was originally packaged in glass containers (Crawford, 1962). Due to the expense involved with returning glass jars, a nonreturnable container in the form of a paper cup was needed (Sanderson, 1957). However, filling paper cups with warm milk to be incubated into yogurt led to a reaction on the coating of these cups. Therefore, the yogurt manufacturing procedure was modified based on changing the culture symbiosis to allow it to be performed at a lower temperature (Sanderson, 1957). A pliable plastic container with a push-on lid also became available (Crawford, 1962). Although most yogurt is currently packaged in plastic containers (polypropylene, polystyrene, or high-density polyethylene), some specialized yogurt products are packaged in flexible tubes or glass jars. Yogurt can be packaged in single-serve containers of varying size or in multi-pack containers.

\section{Protein Denaturation and Acid Coagulation}

Heating milk to a sufficiently high temperature denatures whey proteins, and the denatured whey proteins interact with casein micelles. Rowland (1934) determined the amount of denaturation of albumin and globulin upon heating milk as a function of temperature ranging from 63 to $80^{\circ} \mathrm{C}$ with variable heating times and reported that $83.4 \%$ of the total albumin and globulin became denatured after $30 \mathrm{~min}$ at $80^{\circ} \mathrm{C}$. More recently, Dannenberg and Kessler (1988a) made a graph containing curves of equal degrees of $\beta$-lactoglobulin $\mathrm{B}$ denaturation in milk at various heating time and temperature combinations. Using this graph, an increasing degree of $\beta$-lactoglobulin denaturation led to a relatively uniform decrease in susceptibility of syneresis, regardless of the heating temperature, but the volume of drained whey did not continue to decrease with a longer holding time than is needed to obtain a calculated $99 \%$ denaturation at heating temperatures of 85, 90, and $95^{\circ} \mathrm{C}$ (Dannenberg and Kessler, 1988b). The gel firmness of set-style nonfat yogurt increased with increasing degree of $\beta$-lactoglobulin denaturation up to $60 \%$, and to a lesser degree up to $90 \%$, but not between 90 and 99\% denaturation (Dannenberg and Kessler, 1988c). However, a slight reduction in firmness occurred with increasing holding times beyond the times needed to obtain $99 \%$ denaturation.

Various mechanisms for acid coagulation of milk have been proposed over time. Acid coagulation of the casein micelles occurs because of the lactic acid that is formed during incubation that lowers the $\mathrm{pH}$. Scheele in 1780 and Millon and Commaille in 1865 believed that lactic acid reacting with casein forms an insoluble compound that precipitates while Rochleder in 1843 and Hammarsten in 1877 believed that no definite chemical compound was formed upon acid precipitation of milk casein (Van Slyke and Hart, 1904). Hammarsten in 1874 reported that calcium phosphate is removed from the milk casein upon treatment with acid leading to casein precipitation (Van Slyke and Hart, 1904). Van Slyke and Hart (1904) concluded that casein monolactate (13 to $14 \%$ of the casein) and casein dilactate (86 to $87 \%$ of the casein) were the compounds that formed upon first visual coagulation of casein with lactic acid. Van Slyke and Hart (1904) expected that milk coagulation would occur upon reaching 0.8 to $0.9 \%$ total acidity, whereas Jenness and Patton (1959) stated that casein precipitates upon reaching $\mathrm{pH} 5.2$ to 5.3. The isoelectric point of casein, meaning the $\mathrm{pH}$ at which there is no net electrical charge on the casein micelles, is 4.6. A newer model of acid milk gel formation involves more than just aggregation of the original casein micelles (Heertje et al., 1985). Micellar disaggregation with release of $\beta$-casein and solubilization of colloidal calcium phosphate occurs followed by $\beta$-casein reabsorption to form new particles that differ in structure and composition compared with the original casein micelles. A detailed description of acid coagulation of milk is provided by Lucey and Singh (2003).

\section{Finished Product Characteristics}

Titratable acidity is an important characteristic for yogurt. Crawford (1962) found that a titratable acidity of 0.74 to $0.83 \%$ expressed as lactic acid when placing glass-bottled yogurt into cold storage and a titratable acidity of 0.91 to $0.93 \%$ during cold storage resulted in the most desirable yogurt. An insipid, unattractive yogurt resulted when yogurt with a lower titratable acidity is cooled, whereas a slightly over-acid yogurt resulted when cooled at higher titratable acidities. Galesloot (1958) recommended a titratable acidity of $95^{\circ}$ to $100^{\circ} \mathrm{N}$ 
(equivalent to 0.85 to $0.90 \%$ lactic acid; Crawford, 1962) when ready for consumption. Rosell (1933) reported that yogurt milk acidities can occasionally reach $3.5 \%$ and $\mathrm{pH}$ can drop to nearly 3 in 24 to $36 \mathrm{~h}$.

Surveys have been conducted to determine chemical composition and microbiological quality of yogurt. O'Neil et al. (1979) analyzed 7 brands of plain yogurt and found total solids contents of 13.3 to $16.5 \%$, fat contents of 0.9 to $3.7 \%$, protein contents of 4.4 to $5.3 \%$, titratable acidities of 1.20 to $1.76 \%$, and $\mathrm{pH}$ values of 3.72 to 4.14 , whereas Kroger and Weaver (1973) analyzed 3 plain and 41 fruit yogurts from central Pennsylvania and found total solids contents of 15.10 to $30.73 \%$, fat contents of 0.82 to $2.04 \%$, protein contents of 3.09 to $5.38 \%$, and $\mathrm{pH}$ values of 3.80 to 4.35 . Arnott et al. (1974) analyzed 15 plain and 137 fruit or fruitflavored yogurts manufactured in Ontario and found $15.1 \%$ containing the desired 1:1 ratio of Lactobacillus to Streptococcus, $27.6 \%$ containing staphylococci, $13.8 \%$ containing coliforms, $26.3 \%$ containing yeast counts $>1,000 / \mathrm{g}, 17.8 \%$ containing mold counts $>10 / \mathrm{g}$, and $11.8 \%$ containing psychrotrophic counts $>1,000 / \mathrm{g}$.

Sensory properties and acceptance of yogurt, including drinkable yogurt and Greek yogurt, have been described. Nelson and Trout (1964) claimed that yogurt should have a fine and smooth texture and a firm body so it can hold its shape when it is spooned. The flavor should be clean, distinct, and acidic. Duthie et al. (1977) proposed a scorecard for evaluating the flavor, body and texture, and color of yogurt. Ryan et al. (1984) reported that a red raspberry-flavored yogurt drink and a strawberry-flavored yogurt drink were accepted more often than not by a large-scale consumer taste survey, and Thompson et al. (2007) found only slight differences in preferences in strawberry drinkable yogurts by consumers of different ethnic groups. Harper et al. (1991) found that samples of plain yogurt were judged as too sour and not sweet enough by a consumer panel. Coggins et al. (2008) developed a sensory lexicon for effectively characterizing and differentiating plain yogurt and found that taste and texture characteristics were more important than aroma and appearance in differentiating yogurt treatments. They also reported that fat content of yogurt and whether the milk source was conventional or organic could not be differentiated by descriptive sensory attributes. Hekmat and Reid (2006) reported that the sensory properties of a yogurt containing Lactobacillus rhamnosus and Lactobacillus reuteri were comparable to those of a conventional yogurt. Desai et al. (2013) found that Greek yogurt manufactured both by traditional straining and centrifugation and by addition of dried dairy ingredients were well liked in blinded acceptance testing. A texture that was firm and dense and flavors described as mod- erate sweet aromatic, milkfat, and dairy sour were the preferred attributes of Greek yogurt as determined by external preference mapping (Desai et al., 2013).

Gel strength and viscosity are important yogurt parameters. Firmness of yogurt depends upon the concentration of solids in milk (Pette and Lolkema, 1951). Haque et al. (2001) found that gel strength of set-style yogurt measured by compression testing and viscosity and $\mathrm{G}^{\prime}$ (solid-like character) of stirred samples increase with increasing fermentation temperature during manufacture of yogurt. Walstra et al. (2006) stated that the firmness of set-style yogurt increases when $\mathrm{pH}$ is lowered. Yogurt is a non-Newtonian fluid because it displays decreased apparent viscosity upon increased shear rate.

Syneresis, defined as formation of a top liquid phase (whey) resulting from shrinkage of a gel, is a common problem in yogurt. Yogurt syneresis can be measured by centrifugation and drainage methods (Harwalkar and Kalab, 1983). The latter authors found that susceptibility to syneresis decreased with increasing total solids content in yogurt and with use of preheated milk instead of unheated milk in making yogurt, but only insignificant effects for susceptibility to syneresis were observed with yogurt $\mathrm{pH}$ within the 3.85 to 4.5 range. Lee and Lucey (2004) found that casein particle rearrangement within the gel network and colloidal calcium phosphate solubilization rate affect whey separation and gel strength. They recommended manufacturing yogurt using intermediate to high inoculation rates $(2 \%)$ and then incubating at low temperatures $\left(40^{\circ} \mathrm{C}\right)$ to decrease whey separation and textural defects in the resulting yogurt.

The microstructure of yogurt has been observed by scanning and transmission electron microscopy and by confocal microscopy. Kalab et al. (1975) used scanning and transmission electron microscopy to observe differences in microstructure of unsupplemented yogurt and yogurt containing gelatin, carrageenan, and pregelatinized waxy maize starch. Yogurt was shown to be formed by fusion of casein micelles, forming long chains and, rarely, clusters. Although gelatin addition did not alter the yogurt microstructure, addition of carrageenan led to a fibrillar microstructure without free terminations, and addition of pregelatinized waxy maize starch led to formation of short fibers with frequent free terminations and sheets. Hassan et al. (1995) used confocal scanning laser microscopy to observe gel formation as a continuous process without sample preparation procedures. By observing casein micelle aggregation and loss of bacterial cell mobility, they were able to determine that coagulum formation starts at $\mathrm{pH}$ 5.35. Contraction of the casein network was noted with a further decrease in $\mathrm{pH}$. 


\section{Various Types of Yogurt}

Perceptions about desired fat content of yogurt have changed over time. Davis (1956) stated that yogurt at that time did not have a legal definition in English food law. It was assumed that yogurt was made from whole milk unless it was clearly labeled that it was made with reduced fat or skim milk. However, some reports suggested that the amount of total fat in the diet affects the serum cholesterol level (Hildreth et al., 1951). Therefore, Davis (1956) suggested that it would be better for some people to consume skim milk yogurt instead of whole milk yogurt. Over time, most yogurts became either nonfat or low fat. Low-fat diets increased in popularity in the 1980s and 1990s, and much effort went into producing foods with lower fat contents and improving the flavor and body and texture of foods with lower fat contents so that they more closely resemble their full-fat counterparts. Many low-fat or calorie yogurts were produced and patented about this time, including a low-calorie, low-fat fruit-containing yogurt (Baker, 1983). More recently, it was shown in a large multiethnic cohort study that a higher intake of saturated milk fat was associated with a lower risk of cardiovascular disease (de Oliveira Otto et al., 2012). Even though recent sales of whole milk yogurt are relatively low compared with sales of nonfat and low-fat yogurt, sales of whole milk yogurt are growing rapidly.

Many specialized types of yogurt have been described, including carbonated yogurt, concentrated yogurt, instant yogurt, lactose-free yogurt, aseptic (sterile) yogurt, and directly acidified yogurt. Choi and Kosikowski (1985) developed sweetened plain and strawberry-flavored carbonated yogurt beverages without free whey and found that the latter beverages were well accepted by a consumer panel. A concentrated yogurt obtained by whey drainage was described by Robinson (1977). Greek yogurt (a concentrated yogurt) is now very popular. Forguson (1963) patented an instant yogurt with half the fat content of whole milk; such a yogurt has desirable sensory properties and a long shelf life, and can be formed upon reconstitution with ordinary temperature tap water. Engel (1973) described sweetening yogurt with the use of lactase. A sterile yogurt that will not degrade within 6 mo of unrefrigerated storage was patented by Egli and Egli (1980). Yogurt prepared by direct acidification of milk containing a thickening blend has been patented by Igoe (1979).

\section{Keeping Quality and Safety of Yogurt}

Microbiological factors can affect quality and shelf life of yogurt. Gassem and Frank (1991) pointed out the importance of using milk with low microbial contamination levels and storing milk at low temperatures. Salih et al. (1990) reported that manufacturers indicate an average of $40 \mathrm{~d}$ as shelf life for yogurt. Schulz (1949) stated that yogurt at that time often suffered from high "Coli aerogenes" counts. Hervert et al. (2017) concluded that the hygienic status of yogurt can be appropriately monitored by Enterobacteriaceae testing.

Yogurt and yogurt-like products may contain yeast. Ram Ayyar (1928) observed yeast cells in dahi. Although yeasts are considered contaminants in yogurt, Soulides (1955) isolated non-lactose-fermenting Torulopsis yeasts from yogurt and found that they assisted the survival of $S$. thermophilus and L. bulgaricus, possibly through the removal of some lactic acid by the yeasts. The growth of yeast was found to limit the microbiological shelf life of unflavored and strawberry yogurt during storage at $8^{\circ} \mathrm{C}$ or $20^{\circ} \mathrm{C}$, but lower yeast counts in strawberry yogurt compared with unflavored yogurt were likely related to the presence of potassium sorbate in strawberry puree in the study of Tirloni et al. (2015). Microgard (Wesman Foods Inc., Portland, OR) has been used to inhibit yeast and, later, gram-negative psychrotrophs that appear after extended storage in strawberry-flavored yogurt (Salih et al., 1990).

Although yogurt starter cultures and added probiotics resist pathogens (as will be discussed below in the health benefits section), food poisoning outbreaks involving yogurt have been reported. Verotoxin-producing Escherichia coli O157:H7 in yogurt, most likely due to contamination after pasteurization, led to an outbreak with 16 cases of illness, including 5 cases of hemolytic uremic syndrome after consumption of locally produced flavored yogurt made from pasteurized whole milk in England in 1991 (Morgan et al., 1993). In one case of foodborne botulism involving yogurt, 27 patients in the UK in June 1989 became affected, with 1 death, after consumption of hazelnut yogurt, in which the hazelnut conserve was inadequately processed for destruction of Clostridium botulinum spores, leading to the production of Clostridium botulinum type B toxin (O'Mahony et al., 1990). In another case of foodborne botulism involving yogurt, 10 patients in Turkey in September 2005 developed botulism from type A botulinum toxin in süzme (condensed) yogurt buried under soil (Akdeniz et al., 2007). An outbreak caused by Salmonella typhimurium DT 170 occurred by eating kebabs, doner kebabs, and kebabs with yogurt-based relish, and it was found that raw minced lamb tested positive for Salmonella and that blood-stained, unsealed yogurt pots were stored under a rack of raw lamb (Evans et al., 1999). A food poisoning outbreak at a military hospital in Strasbourg, France, in 1964 was caused by consumption of a raspberry-flavored yogurt that contained 1 
$\times 10^{8}$ staphylococci per gram of yogurt (Mocquot and Hurel, 1970). One of the risk factors involved in the epidemic of 149 cases of diphtheria in Yemen Arab Republic between August 1981 and January 1982 was the consumption of factory-made yogurt (Jones et al., 1985). One case of Geotrichum sp. in yogurt has been reported, resulting from mishandling of food in Canada in 1975 (Todd, 1978). A food-borne fungal pathogen, Mucor circinelloides f. circinelloides, caused more than 200 consumers to become ill with nausea, vomiting, and diarrhea after consumption of Greek yogurt in the United States in 2013 (Lee et al., 2014).

A pathogen of major concern to the dairy industry is Listeria monocytogenes. This organism appeared to be observed as early as 1891 (Gray and Killinger, 1966). Listeria monocytogenes, as it is known today, was first described in detail by Murray et al. (1926). Gray and Killinger (1966) believed that more emphasis should be placed on the seriousness of L. monocytogenes. The outbreak of listeriosis from pasteurized milk in Massachusetts (Fleming et al., 1985) and from Mexican-style cheeses (Linnan et al., 1988) increased the awareness of L. monocytogenes and listeriosis within the dairy industry. As a result, the number of research papers involving $L$. monocytogenes in dairy products, including yogurt and other cultured dairy products, has increased substantially since the 1980s.

Various techniques have been used to detect $L$. monocytogenes in yogurt. Siragusa and Johnson (1988) compared various agars for recovering $L$. monocytogenes that was inoculated into yogurt and proposed use of Listeria selective isolation agar and modified acriflavin ceftazidime esculin agar. They also found that use of an enrichment procedure lead to recovery of $L$. monocytogenes on various agars that were not found by direct plating. Cox et al. (1998) developed a PCR-based fluorogenic 5 '-nuclease assay for the rapid and sensitive detection of $L$. monocytogenes in various types of dairy products including yogurt and buttermilk.

Surveys of presence of Listeria in yogurt have been conducted. A survey of various milk and milk products in Ethiopia revealed that 2\% of yogurt samples were contaminated with L. monocytogenes and $2 \%$ were contaminated with Listeria innocua (a nonpathogenic species; Muhammed et al., 2013). Another survey found $10.71 \%$ of yogurt samples in Sri Lanka to be contaminated with L. monocytogenes (Wijendra et al., 2014). However, Listeria spp. were not found in the studies of Kerr et al. (1992), Ubeyratne et al. (2014), or Abdimoghadam et al. (2015).

Challenge studies in which Listeria have been added to yogurt to determine their survival have been performed. In an early study, Ikonomov and Todorov (1964) found no L. monocytogenes serotypes 1 and 4b at 24 to $40 \mathrm{~h}$ when storing ewe milk yogurt at 18 to $22^{\circ} \mathrm{C}$ but found a survival period of more than $6 \mathrm{~d}$ at a storage temperature of $10^{\circ} \mathrm{C}$. Choi et al. (1988) found that L. monocytogenes will survive 13 to $27 \mathrm{~d}$ in vanilla-flavored yogurt after inoculation of $10^{4}$ to $10^{5}$ cells, whereas Tirloni et al. (2015) reported that $L$. monocytogenes with a starting concentration of either 2 or $5 \log \mathrm{cfu} / \mathrm{g}$ was still detected in $25 \mathrm{-g}$ samples of unflavored and strawberry yogurt at $68 \mathrm{~d}$ of storage. Szczawiński et al. (2016) developed linear and polynomial models to describe the inactivation rate of $L$. monocytogenes in yogurt as a function of temperature and found D-values (decimal reduction time) ranging from $87.0 \mathrm{~h}$ at a storage temperature of $15^{\circ} \mathrm{C}$ to 243.9 $\mathrm{h}$ at a storage temperature of $6^{\circ} \mathrm{C}$ when calculated from linear models.

Acidity affects the survival of $L$. monocytogenes in yogurt. Siragusa and Johnson (1988) found that $L$. monocytogenes in yogurt with a $\mathrm{pH}$ of 4.1 could survive up to $9 \mathrm{~d}$ when using enrichment steps for their recovery. Hill et al. (1995) inoculated an acid-tolerant mutant strain of L. monocytogenes and its parental strain into yogurt with a $\mathrm{pH}$ of 4.3 and stored at $4^{\circ} \mathrm{C}$ and found that the mutant strain had a higher survival rate than its parental strain due to acid adaptation of the mutant strain.

High-pressure processing of ayran, a popular traditional yogurt drink in Turkey, applied at $600 \mathrm{MPa}$ for $300 \mathrm{~s}$ at ambient temperature decreased L. monocytogenes and L. innocua counts by greater than $5 \log$ units without significantly changing the $\mathrm{pH}$, water activity, color, or serum protein separation of ayran (Evrendilek and Balasubramaniam, 2011). The same extent of inactivation can be accomplished with a pressure reduction of 100 to $300 \mathrm{MPa}$ or with a time reduction of $210 \mathrm{~s}$ with the addition of mint essential oil.

Salmonella is another pathogen of major concern to the dairy industry. Emanuiloff (1941) reported the viability of Salmonella in yogurt. Ghoniem (1971) showed that Salmonella typhimurium survived for $68 \mathrm{~d}$ during freezing $\left(-1^{\circ} \mathrm{C}\right), 23 \mathrm{~d}$ at $4^{\circ} \mathrm{C}$ storage, and $19 \mathrm{~d}$ at 30 to $32^{\circ} \mathrm{C}$ storage, whereas $S$. typhi survived for only 30 $\mathrm{d}$ during freezing, $16 \mathrm{~d}$ at $4^{\circ} \mathrm{C}$ storage, and $11 \mathrm{~d}$ at room temperature storage when cans of buffalo milk yogurt were inoculated with $5 \mathrm{~mL}$ of Salmonella. Álvarez-Ordóñez et al. (2013) showed that counts of both acid-adapted and non-acid-adapted cells of Salmonella enterica serovar typhimurium only decreased between 1.3 and $1.9 \log$ units when stored at 4,10 , or $25^{\circ} \mathrm{C}$ for $43 \mathrm{~d}$ but decreased about $4 \log$ units at $37^{\circ} \mathrm{C}$ for $43 \mathrm{~d}$.

Surveys and investigations for presence of other pathogens in yogurt have been conducted. Yersinia enterocolitica was found in homemade yogurt (made from pasteurized milk) that was involved in an outbreak in 
Pennsylvania in 2011 (Centers for Disease Control and Prevention, 2011). Omara et al. (2015) analyzed yogurt samples in Egypt for the presence of Campylobacter jejuni and found $4.4 \%$ to be positive by isolation and biochemical identification and $1.2 \%$ to be positive by PCR detection of the MapA gene. Amer et al. (2010) found that enterohemorrhagic Escherichia coli and Yersinia enterocolitica were no longer present during storage for 10 and $4 \mathrm{~d}$, respectively. Bacillus cereus was isolated from 1 of 30 yogurt samples (San et al., 2012).

Challenge studies in which various pathogens have been inoculated into yogurt to determine the extent of survival have been performed. Dineen et al. (1998) found E. coli $\mathrm{O} 157: \mathrm{H} 7$ in yogurt for up to $12 \mathrm{~d}$ after inoculation of $10^{3} \mathrm{cfu} / \mathrm{mL}$ of this pathogen into yogurt. Hudson et al. (1997) reported that post-processing contamination of yogurt could lead to survival of enterohemorrhagic E. coli O157:H7, even in highly acidic environments at refrigeration temperatures. They reported survival between 5 and $17 \mathrm{~d}$ after inoculating a bioluminescent strain of E. coli $\mathrm{O} 157: \mathrm{H} 7$ into commercial yogurt. Tirloni et al. (2015) reported that E. coli was still detected in 25-g samples of unflavored yogurt at 26 $\mathrm{d}$ of storage with a starting concentration of $2 \log \mathrm{cfu} / \mathrm{g}$ and up to $47 \mathrm{~d}$ with a starting concentration of $5 \mathrm{log}$ cfu/g. Aytaç and Özbas (1994) found that Yersinia enterocolitica survived at least $26 \mathrm{~d}$ when inoculated into milk to be made into yogurt but Aeromonas hydrophila did not survive $5 \mathrm{~d}$ after inoculation. Enterobacter sakazakii grew during the early stages of fermentation in the manufacture of plain yogurt, but their population significantly decreased during the cooling and storage steps, due to the low pH (Shaker et al., 2008).

Pathogens leading to tuberculosis and Crohn's disease have been studied in yogurt. Tuberculosis originating from yogurt is a concern in areas where unpasteurized milk is used. DeGrolier (1939) isolated virulent bovine tubercle bacilli (now Mycobacterium tuberculosis) from 1 out of 8 yogurt samples. Van Brandt et al. (2011) reported that Mycobacterium avium ssp. paratuberculosis (the likely causative agent in Crohn's disease) could survive in yogurt for 6 wk. Nasr et al. (2014) inoculated Mycobacterium bovis (the causative agent for bovine tuberculosis) at $10^{3} \mathrm{cfu} / \mathrm{mL}$ and $10^{5} \mathrm{cfu} / \mathrm{mL}$ into yogurt and found that it could survive for $7 \mathrm{~d}$.

\section{OTHER CULTURED DAIRY PRODUCTS}

\section{Sour Cream and Acidified Sour Cream}

Sour cream and acidified sour cream are legally described in 21CFR131.160 (CFR, 2017d) and 21CFR131.162 (CFR, 2017e), respectively. Sour cream is soured by lactic acid bacteria and acidified sour cream is prepared with safe and suitable acidifiers, with or without use of lactic acid bacteria, and the titratable acidity of both of these products is at least $0.5 \%$, expressed as lactic acid. These products contain at least $18 \%$ milkfat before addition of nutritive sweeteners and bulky flavors, but at least $14.4 \%$ milkfat after addition of these ingredients. Optional ingredients include ingredients that improve texture, prevent syneresis, or prolong shelf life as well as rennet, nutritive sweeteners, salt, and flavoring ingredients either with or without coloring. Additionally, sour cream may contain up to $0.1 \%$ sodium citrate added before culturing as a flavor precursor.

An old method of producing sour cream was to hold cream at a suitable temperature to allow native bacteria to produce acid, allowing the cream to sour (Page and Lavalie, 1955). However, this procedure results in the separation of whey from the curd and in off-flavors due to the growth of undesirable bacteria, yeasts, and molds.

Doan and Dahle (1928) studied the effects of various parameters on the body of the resulting sour cream and developed a recommended manufacturing procedure. They found that a thicker body could be obtained by using higher pressures during homogenization and higher temperatures during pasteurization; increasing fat content; adding extra solids, rennet, or gelatin; and ripening after packaging. Therefore, their recommended manufacturing procedure was standardizing cream to at least $18 \%$ fat, pasteurizing at a temperature of at least $82^{\circ} \mathrm{C}$ for at least $10 \mathrm{~min}$, homogenizing at this temperature using a pressure of at least $13.8 \mathrm{MPa}$, cooling to $21^{\circ} \mathrm{C}$, adding a sufficient amount of starter to ripen the product to about $0.6 \%$ acidity, packaging with minimal agitation, cooling to $4{ }^{\circ} \mathrm{C}$, and aging for 12 to $24 \mathrm{~h}$ before marketing.

More recently, Kosikowski and Mistry (1997) described sour cream production by standardizing fresh cream to about $19 \%$ fat, adding up to $0.5 \%$ stabilizer and about $0.2 \%$ citric acid, pasteurizing and homogenizing, cooling to about $22^{\circ} \mathrm{C}$, inoculating with a commercial mesophilic lactic acid starter (Lactococcus lactis ssp. cremoris and L. lactis ssp. lactis), possibly adding a rennet extract, agitating gently for a few minutes, incubating until the desired $\mathrm{pH}$ (about 4.5 to 4.6) and acidity (about $0.70 \%$ ) are reached, chilling, and packaging. Dual homogenization may be performed to obtain a heavy-bodied sour cream. Alternatively, the incubation may be performed in the consumer package.

Research has been performed on sour cream flavor and flavor-active compounds. Hempenius et al. (1969) determined that a volatile acidity requiring $1.2 \mathrm{~mL}$ of $0.1 \mathrm{~N} \mathrm{NaOH}$ to neutralize and $1 \mathrm{ppm}$ of diacetyl were the flavor thresholds for these compounds in sour 
cream. Harper (1968) reported that 0.65 to $0.80 \%$ lactic acid was the optimal level to achieve the desired taste of sour cream. Shepard et al. (2013) performed a study to explain consumer acceptance of sour cream by their chemical and sensory properties. They found that sour creams characterized by the flavor-active compounds of diacetyl, acetoin, $\delta$-decalactone, and 2-methyl-3-furanthiol were judged as the most desirable. Also, they reported that the characteristics of moderate to high levels of diacetyl, milk fat, and cooked/milky flavors but low to moderate levels of sour taste and sour aromatics with moderate degrees of denseness and firmness for sour cream would be desirable to most consumers.

Viscosity is an important property for sour cream. Hilker (1947) developed a procedure for relating the resistance of penetration of a plummet to the visual viscosity of sour cream. Little (1967) reported that the ideal viscosity ranges from 140,000 to $250,000 \mathrm{cP}$. Manufacturing cultured sour cream with a lactic culture that has a slight tendency toward ropiness will lead to a sour cream with a high viscosity and a very smooth texture (Babel, 1967).

Values for shelf life of sour cream have been reported. Page and Lavalie (1955) developed a procedure for producing a protein-fortified sour cream-like product with a firm body that is not too susceptible to syneresis, and the shelf life was prolonged from about $4 \mathrm{~d}$ to about 20 $\mathrm{d}$ by incorporating a pasteurization and homogenization step after the product reached the proper degree of acidity. More recently, Salih et al. (1990) found that manufacturers reported an average shelf life of $31 \mathrm{~d}$ for sour cream.

A probiotic, low-calorie sour cream containing $L$. acidophilus, Bifidobacterium, and S. thermophilus was developed by Fayed et al. (2006). A fat substitute called Simplesse 100 (CP Kelco, Atlanta, GA) was added to mimic milk fat, and dried whey protein concentrate was used as a bulking agent to replace the total solids.

Commercial production of sour cream by direct acidification started in 1962 (Little, 1967). A stabilizer was found to effectively promote a firm body in this type of sour cream. Acidified sour cream did not receive complaints about its flavor.

\section{Cultured Butter and Cultured Buttermilk}

Some butter is made from cultured cream. Conn (1889) described the advantages of ripening cream for buttermaking as a better separation of butter from ripened cream than from sweet cream, better keeping quality of butter, and improved butter flavor. Early methods of ripening cream for butter making include spontaneous souring (no addition of special souring methods) or addition of either buttermilk (either fresh or from the previous day) or sour cream (cream that was ready for churning), but problems with contamination often occurred. Afterward, acid-producing cultures were prepared and shipped to dairymen in liquid form, but the problem of long transport of liquid cultures under unfavorable conditions led to production of cultures in the dry state in the 1890s (Knudsen, 1931). An improved manufacturing procedure for cultured butter from ripened cream was patented by Vilhelm Storch (1893) by performing a $70^{\circ} \mathrm{C}$ to $80^{\circ} \mathrm{C}$ heat treatment on the cream or milk, adding a pure culture of certain types of flavor producing bacteria obtained from fresh butter, fully ripened cream, or fresh buttermilk for ripening, and finally churning. Storch (1893) reported that the flavor of cultured butter results more from the action of bacteria than from the feed consumed by the cows. Adding butter culture directly to butter was also discussed by Babel and Hammer (1944).

It was generally thought before 1919 that butter cultures were pure lactic acid streptococci cultures (Hammer and Babel, 1943). In 1919, 3 separate studies (Boekhout and Ott de Vries, 1919; Hammer and Bailey, 1919; Storch, 1919; cited in J. Dairy Sci., 1943, 26:160-166) showed that other cultures were also present, as discussed by Hammer and Babel (1943). Cultures that are now used include Lactococcus lactis ssp. lactis, Lactococcus lactis ssp. cremoris, Lactococcus lactis ssp. lactis biovar diacetylactis, and Leuconostoc mesenteroides ssp. cremoris (Frede, 2003).

Due to the disappearance of citric acid within 2 to 4 d in milk, Templeton and Sommer (1929) added citric acid and sodium citrate to ordinary commercial cultures, leading to increased production of volatile acidity by about $50 \%$, with only a $10 \%$ increase in acidity, and these cultures in milk were often preferred organoleptically over untreated milk cultures. Likewise, Templeton and Sommer (1935) reported that use of citric acid and sodium citrate in the cream or in the starter in manufacturing butter leads to a more desirable flavor and aroma.

Much research has been performed on identifying flavor compounds in butter cultures and improving flavor of butter. Michaelian et al. (1933) reported that diacetyl was detected by Schmalfuss in 1928 by the detection of its aroma in a milk culture and was found by van Niel, Kluyver, and Derx in 1929 to be responsible for, or at least the main component of, the aroma of butter. Satisfactory butter cultures were found to contain considerable amounts of acetylmethylcarbinol (also known as acetoin or 3-hydroxy-2-butanone) and diacetyl, whereas butter cultures lacking flavor contained either smaller amounts or none of these compounds (Michaelian et al., 1933). Citric acid can be broken down to acetylmethylcarbinol, which can be oxidized to diacetyl. Because 
acetylmethylcarbinol does not directly contribute to the aroma of butter, it would be advantageous to convert acetylmethylcarbinol to diacetyl. The yield of diacetyl from acetylmethylcarbinol can be increased by subjecting the butter cultures to pressure and stirring as explained by Werkman and Hammer (1940). Lindsay et al. (1965b) identified many volatile flavor components (aldehydes, methyl ketones, primary and secondary alcohols, methyl and ethyl esters of the normal aliphatic acids, and sulfur compounds) of a commercial mixedstrain butter culture.

Michaelian et al. (1933) found a large effect of acidity on acetylmethylcarbinol plus diacetyl production by citric acid-fermenting streptococci. This observation supports the finding of very rapid formation of acetylmethylcarbinol plus diacetyl, and the occurrence of butter flavor and aroma, late in the ripening of the butter cultures. This effect of acid also explains the characteristic odor that developed when lactic acid bacteria were added to a milk culture that was observed in 1919 by Bockhout and Ott de Vries, as reported by Michaelian et al. (1933).

The aroma bacteria used in starter cultures for making butter in the Netherlands were originally Leuconostoc cremoris (Badings and Galesloot, 1962). Starting around about 1950, Streptococcus diacetylactis (now Lactococcus lactis ssp. lactis biovar. diacetylactis; described by Matuszewski et al., 1936) or S. diacetylactis plus L. cremoris also began to be used. A flavor defect referred to as "yogurt flavor" started occurring. Badings and Galesloot (1962) found that the use of the $S$. diacetylactis cultures led to this flavor defect. Lindsay et al. (1965a) reported that the green flavor (yogurtlike) occurs when the diacetyl-to-acetaldehyde ratio becomes less than 3:1.

Cultured milk, including cultured buttermilk, is described in 21CFR131.112 (CFR, 2017f). Optional dairy ingredients, including cream, milk, partially skim milk, or skim milk, either alone or in combination, are cultured with characteristic microbial organisms so that a titratable acidity of at least $0.5 \%$, expressed as lactic acid, is obtained. Cultured milk must be pasteurized or ultra-pasteurized before adding culture. Other optional ingredients that may be used include vitamin A and D, certain other dairy ingredients, nutritive carbohydrate sweeteners, flavoring ingredients, color additives that do not simulate color of milkfat or butterfat, stabilizers, butterfat or milkfat, aroma- and flavor-producing microbial cultures, salt, and up to $0.15 \%$ citric acid (or an equivalent amount of sodium citrate) as a flavor precursor.

To more effectively use creamery by-products for human consumption, Finkelstein (1917) reported that addition of $25 \%$ Bacillus bulgaricus (L. bulgaricus) cul- tures to buttermilk derived from pasteurized ripened cream reduces a tendency for wheying off and improves the body and flavor of buttermilk. Although real buttermilk is the by-product of ripened cream after churning, cultured buttermilk is the product resulting from the addition of cultures to milk.

Conventional and alternative procedures for manufacturing cultured buttermilk have been reported. Cultured buttermilk is produced by adding salt and citric acid to milk, heating to $85^{\circ} \mathrm{C}$ for $30 \mathrm{~min}$ or $88^{\circ} \mathrm{C}$ for 2 min, cooling to $22^{\circ} \mathrm{C}$, inoculating with lactic starter culture (Lactococcus lactis ssp. lactis or L. lactis ssp. lactis biovar diacetylactis), incubating for about 14 to $16 \mathrm{~h}$, breaking the curd when the titratable acidity reaches $0.80 \%$, cooling to $10^{\circ} \mathrm{C}$ or lower with gentle agitation, and packaging as described by Kosikowski and Mistry (1997). Buttermilk can also be made by direct acidification by lowering the $\mathrm{pH}$ to about 4.8 to 5.1 from the first addition and then to about 4.2 to 4.5 in the second addition (Corbin and Long, 1967). Buttermilk made this way does not whey off after 2 wk of refrigerated storage, and this product can retain its original viscosity, body, flavor, and appearance for up to about 1 mo under refrigeration. Corbin and Long (1967) claimed that otherwise cultured buttermilk has a shelf life of only about $5 \mathrm{~d}$ because of the difficulty in controlling the bacterial fermentation within the cultured buttermilk. Roberts et al. (1971) reported that manufacturing cultured buttermilk by preacidifying milk to $\mathrm{pH} 5.2$ using concentrated hydrochloric acid before inoculation and incubation with lactic starter cultures resulted in a more consistent product and this product was preferred by experienced judges compared with the control cultured buttermilk. Flakes or granules of butter can be added to buttermilk to make flake buttermilk by the Vogt method as described by Guthrie (1935).

Flavor, spoilage, and shelf life of cultured buttermilk have been studied. The quality of cultured buttermilk in terms of flavor has often been criticized (Keenan et al., 1968). Wang and Frank (1981) isolated various species of Pseudomonas, Enterobacter, Acinetobacter, Escherichia, and Actinobacillus and detected yeast and mold in commercial cultured buttermilk. They found that these psychrotrophic bacteria and yeast can reduce diacetyl to varying degrees. Salih et al. (1990) reported that manufacturers indicate an average of $17 \mathrm{~d}$ as the shelf life for buttermilk.

Methods to improve cultured buttermilk have been reported. Kosikowski (1969) reported that concentrated purees or fruit juices could be added to cultured buttermilk to form orange-, pineapple-, strawberry-, raspberry-, lemon-, and lime-flavored cultured buttermilks and found that the most acceptable flavor was strawberry. Rodas et al. (2002) prepared probiotic 
buttermilk by adding Lactobacillus reuteri without significantly affecting composition, proteolysis, or sensory quality compared with the control. The buttermilk maintained greater than $10^{6} \mathrm{cfu} / \mathrm{mL}$ for $10 \mathrm{~d}$ of storage when adding this probiotic strain at $1 \%$ before buttermilk fermentation. Antunes et al. (2012) achieved Bifidobacterium animalis $\log$ counts of $8.5 \mathrm{cfu} / \mathrm{mL}$ in strawberry-flavored buttermilk sweetened with sucrose and sucralose.

\section{Acidophilus Milk}

Acidophilus milk has been referred to either as milk fermented with $L$. acidophilus or an unfermented milk containing L. acidophilus. Cheplin and Rettger (1920b) described Bacillus acidophilus (L. acidophilus) milk as possessing desirable sensory properties and it was prepared by growing these organisms in milk to produce a soft curd within $24 \mathrm{~h}$. However, Myers (1931) claimed that ordinary cultured acidophilus milk has an unpleasant taste, and lactic acid was not important in transforming the intestinal flora. To utilize acidophilus therapy without the unpleasant taste, Myers (1931) described an unfermented acidophilus milk in which high concentrations of viable $L$. acidophilus were suspended while retaining the taste and physical properties of rich whole milk. Lactobacillus acidophilus counts in unfermented acidophilus milk do not decrease as rapidly as in sour acidophilus milk, and the milk may be kept sweet for up to $7 \mathrm{~d}$ when stored at 2 to $5^{\circ} \mathrm{C}$ (Myers, 1931). Acidophilus milk products were reviewed by Gilliland (1989).

\section{Kefir}

Kefir is a fermented milk product that has been manufactured traditionally for centuries in the Caucasus Mountains (Stepaniak and Fetliński, 2003). Kefir grains, resembling miniature cauliflower florets and consisting of a wide variety of symbiotic yeasts, Lactobacillus, Lactococcus, and Leuconostoc, are added to milk in kefir manufacturing. The detailed manufacturing procedures for traditional and industrially produced kefir are diagrammed in Stepaniak and Fetliński (2003). Although lactic acid is the main fermentative metabolite in kefir, a small amount of alcohol is also produced. Pronounced effervescence from carbon dioxide is present in traditional kefir. Kolakowski and Pawlikowska (2012) successfully incorporated the probiotics Bifidobacterium lactis HN019, L. acidophilus NCFM, and L. rhamnosus HN001 into kefir. Recently, O'Brien et al. (2017) reported that kefir was acceptable to cancer survivors after exercising.

\section{Yakult}

Yakult (Yakult Honsha Co.) was launched in 1935 and is a Japanese milk drink fermented by Lactobacillus casei Shirota until a titratable acidity of $2 \%$ is reached (Tamime et al., 2007). The resulting curd is broken, sweetened, flavored, homogenized at $15 \mathrm{MPa}$, and diluted with water before being packaged into plastic bottles. The $L$. casei Shirota strain is indigenous in the human intestinal tract (Akuzawa and Surono, 2003).

\section{HEALTH BENEFITS PROVIDED BY YOGURT AND OTHER CULTURED DAIRY PRODUCTS}

There are various early claims of the therapeutic value of yogurt and other cultured dairy products. People from the Middle East and Asia have consumed yogurt - and likely have known that yogurt consumption provided health benefits - for thousands of years. The severe diarrhea of King Francis I of France was successfully treated by prescribing yogurt back in the 1500s (Hume, 2011). Jagielski (1871) mentions the therapeutic value of koumiss without describing the scientific background in his patent dealing with the production of an artificial koumiss from milk of various species.

Leeds (1888) did not see health benefits that would be provided by fermented milk products for invalids and infants. He stated that the effect of matzoon (an Armenian fermented milk product similar to yogurt) on treatment of severe gastric disorders and general debility was not strong enough to form a favorable opinion of its effectiveness. Also, he did not believe that matzoon was suitable as an infant food based on its analysis, and he noted that the milk sugar was converted into lactic acid, alcohol, and other fermentation products.

Elie Metchnikoff (1908) thought that many ailments in people were caused by toxins produced by putrefactive bacteria in the intestinal tract. If these putrefactive bacteria could be limited or eliminated in the intestinal tract, he believed that people could live longer. He noted that many Balkan peasants live very long lives and thought that it was due to their high consumption of sour milk containing large numbers of lactobacilli. The acid production by these lactobacilli in the human intestinal tract was thought to discourage putrefactive bacterial growth, leading Metchnikoff to encourage the consumption of sour milk to promote growth of L. bulgaricus in the intestinal tract.

Because of Metchnikoff's beliefs, the survival of cultures within the gastrointestinal tract from ingested sour milk became an important research topic. Herter and Kendall (1908) fed milk fermented with Bacillus bulgaricus ( $L$. bulgaricus) to a rhesus monkey and 
found that lactic acid could be detected, especially above the ileo-cecal region, but this microorganism did not establish itself in relatively large numbers. Also, Cheplin and Rettger (1920b) were not able to implant Bacillus bulgaricus into the intestines of man. However, they were able to implant Bacillus acidophilus (Lactobacillus acidophilus) into the intestinal tract of human subjects by daily consumption of $500 \mathrm{~mL}$ to $1 \mathrm{~L}$ of acidophilus milk culture. Therefore, Cheplin and Rettger (1920a) believed that Metchnikoff might have confused L. bulgaricus with $L$. acidophilus because they closely resemble each other. Also, Cheplin and Rettger (1920a) claimed that beneficial effects provided by consumption of yogurt and other sour milk products likely resulted from the milk itself instead of their acid-producing bacteria.

Rotch and Kendall (1911) noted that Bacillus acidophilus grew better below the ileo-cecal valve compared with above it, as is the case for $B$. bulgaricus. They suggested the therapeutic use of B. acidophilus based on many factors including its ability to inhibit and replace foreign invading bacteria in the large intestines.

However, recent studies have indicated that yogurt bacteria can survive transit in the human gastrointestinal tract because these organisms can be recovered in feces (Mater et al., 2005; Elli et al., 2006). Conway et al. (1987) believed that the adhesion mechanism of $L$. bulgaricus, L. acidophilus, and S. thermophilus to both human and pig intestinal cells was probably nonspecific. Berrada et al. (1991) emphasized the importance of choosing an acid-resistant strain of Bifidobacterium in manufacturing bifidus-fermented milks because they showed that Bifidobacterium in one brand of commercial fermented milk survives well in vitro and in vivo, whereas Bifidobacterium from another brand did not survive well in these tests.

Although food poisoning outbreaks involving yogurt have been reported, as discussed above, some protection against pathogens and intestinal infections from yogurt consumption is provided by its acidity or by inhibitory substances produced by added cultures. Emanuiloff (1941) reported that the degree of acidity affects the viability of Salmonella in yogurt, and Ozek (1942) reported that Salmonella (including S. typhi), Shigella, and Brucella spp. could be killed in yogurt because of yogurt acidity. Likewise, Rubin and Vaughan (1979) reported that almost all of the bactericidal activity of yogurt against Salmonella typhimurium at $37^{\circ} \mathrm{C}$ was caused by lactic acid under the conditions of their experiment, but this pathogen was partially protected by the casein fraction of yogurt. However, Todorov (1967) reported that exposure to milk products, including yogurt, changed the morphological, cultural, biochemical, and serological properties of various strains of Salmonella, and this change was caused by inhibitory substances produced by starter cultures. Also, Lucca (1975) concluded that antibacterial activity was due more to substances of an antibiotic nature formed by organisms within the yogurt than due to the yogurt acidity. Attaie et al. (1987) reported that Staphylococcus aureus was inhibited in acidophilus yogurt more than in regular yogurt, probably because of bacteriocin production by L. acidophilus.

Lactobacillus acidophilus and L. reuteri have been shown to inhibit pathogens. White and Hill (1949) found that L. acidophilus inhibits the growth of Aerobacter aerogenes (Enterobacter aerogenes), possibly due to lactic acid production. Shahani et al. (1976) noted strong inhibitory effects of an inhibitory compound from L. acidophilus against 8 pathogens, and Shahani et al. (1972) patented the antibiotic acidophilin that is produced by various strains of L. acidophilus, especially L. acidophilus DDS 1 . Recently, Ortiz-Rivera et al. (2017) showed that reuterin produced by L. reuteri ATCC 53608 can inactivate pathogenic (S. aureus, Salmonella enterica ssp. enterica, and L. monocytogenes), pathogen indicator (E. coli DH5 $\alpha$ ), and spoilage (Penicillium expansum) microorganisms.

Studies have shown that yogurt and other cultured dairy products can alleviate diarrhea and shorten colonic transit time. Milk artificially soured by lactic acid organisms (Marriott, 1919) and whole milk acidified by lactic acid (Marriott and Davidson, 1923) have been recommended as a routine infant food to treat gastrointestinal disturbances. Consumption of yogurt containing Lactobacillus GG decreased incidents of antibiotic (erythromycin)-associated diarrhea, abdominal distress, stomach pain, and flatulence in healthy volunteers compared with consumption of pasteurized yogurt (Siitonen et al., 1990). Likewise, consumption of a fermented milk product containing Lactobacillus GG compared with a pasteurized yogurt was effective in promoting recovery from acute rotavirus diarrhea in young children (Kaila et al., 1992). Marteau et al. (2002) performed a double-blind crossover study for determining effect of ingestion of a milk fermented with B. animalis DN-173 010 on colonic transit time in healthy women and found that the total and sigmoid transit times were reduced with $B$. animalis consumption without significantly affecting other transit times or fecal weight, $\mathrm{pH}$, bacterial mass, and bile acids.

Some studies have shown that immunity can be enhanced by consumption of yogurt or other cultured dairy products. Hatakka et al. (2001) found a reduction in the number of respiratory infections and its severity in young children whom consumed a probiotic milk containing Lactobacillus GG in a randomized, double blind, placebo controlled study. Although consumption 
of milk fermented with yogurt cultures and L. casei DN114001 for $3 \mathrm{wk}$ did not reduce the incidence of winter infections in elderly people, the duration of infections was reduced compared with the control group (Turchet et al., 2003). Parra et al. (2004) concluded that daily consumption of fermented milk containing L. casei DN-114001 by healthy middle-aged adults improved their innate immune defense. However, Spanhaak et al. (1998) performed a double-blind placebo-controlled study to determine the effect of consumption of $L$. casei Shirota-fermented milk on the intestinal microflora and immune parameters in healthy subjects and found increases in the Lactobacillus and Bifidobacteria counts in their fecal microflora; these authors could not show distinct effects on immune responses.

The nutritional value and protein digestibility of yogurt have been reported. Forster (1931) found that contents of vitamins $\mathrm{A}$ and $\mathrm{D}$ are higher but contents of vitamins $\mathrm{B}$ and $\mathrm{C}$ are lower in yogurt compared with an equal weight of milk used to prepare it. Hernandez and Park (2014) quantified the contents of 20 minerals in both cow milk yogurt and in goat milk yogurt. Lee et al. (1988) showed that digestibility of protein in fermented yogurt is higher than that of heated milk when fed to rats.

Lactose digestion can be improved by consumption of yogurt and other fermented milk. Bayless and Huang (1969) reported that people in Mashona tribes in Salisbury, Rhodesia (now Harare, Zimbabwe) could tolerate large amounts of milk soured by a traditional ritual even though they are lactose intolerant. Baer (1970) suggested that yogurt consumption might be suitable for people who cannot digest lactose because of the reduced lactose content in yogurt resulting from fermentation. Goodenough and Kleyn (1976) found that lactase present in yogurt might be active in the small intestine of rats upon yogurt consumption. Kim and Gilliland (1983) were able to show improved lactose utilization in individuals who were lactose malabsorbers by their consumption of milk with added L. acidophilus. Kolars et al. (1984) reported enhanced absorption of lactose from yogurt compared with lactose from milk as determined by breath hydrogen measurements in lactase-deficient subjects and fewer cases of diarrhea or flatulence from yogurt consumption compared with consumption of similar amounts of lactose from either milk or a water solution. Hertzler and Clancy (2003) showed that kefir consumption improved lactose digestion and tolerance in adults who have lactose maldigestion.

Serum cholesterol can be decreased by yogurt and fermented milk consumption. Mann and Spoerry (1974) found decreases in blood cholesterol levels in young Maasai men (a tribe from Kenya) after excessive intake of milk fermented with a wild culture of Lactobacillus and suggested this decrease was likely caused by a factor in sour milk that affects cholesterol metabolism. Later, Mann (1977) reported that the lower cholesteremia resulting from consumption of a large amount of yogurt was likely from the inhibition of the regulatory enzyme hydroxymethyl glutaryl CoA reductase (EC 1.1.1.3.4) by hydroxymethyl glutarate. Consumption of yogurt containing the probiotics Lactobacillus acidophilus La5 and Bifidobacterium lactis Bb12 led to a 4.54\% decrease in total serum cholesterol and a $7.45 \%$ decrease in low density lipoprotein cholesterol compared with consumption of conventional yogurt in individuals with type 2 diabetes mellitus (Ejtahed et al., 2011).

Many studies have been performed to investigate the effect of yogurt consumption on risk of becoming overweight or obese or developing metabolic syndromes. Mozaffarian et al. (2011) performed a study to relate dietary and lifestyle habits to weight changes for 3 separate cohorts and found a 4-yr multivariable-adjusted loss of $0.82 \mathrm{lb}$ per increased daily serving of yogurt. Sayon-Orea et al. (2017) concluded that cohort studies tended to find an inverse relationship between yogurt consumption and becoming overweight or obese and a decreased risk of developing metabolic syndrome.

Yogurt consumption may reduce the likelihood of tumor formation and certain types of cancer. Reddy et al. (1973) found lower total tumor cell counts and DNA content of cells in yogurt-fed male Swiss mice with Ehrlich ascites tumor transplants compared with their control. In a later study, Reddy et al. (1983) reported that yogurt had its greatest anti-tumor effect in the early stages of tumor growth and that tumor cell progression was not affected by milk or by lactic acid. Also, they centrifuged the yogurt into solids and supernatant and found that the anti-tumor activity was localized in the solids fraction rather than in the supernatant fluid fraction. Ayebo et al. (1981) fractionated yogurt and concluded that components having a molecular weight less than 14,000 and not chemically bound to any larger compounds may be responsible for the antitumor activity of yogurt. Pala et al. (2011) found that increased yogurt consumption was associated with decreased risk of colorectal cancer in a cohort study. Shida and Nomoto (2013) concluded that L. casei Shirota protects against bladder cancer.

A few additional health benefits are obtained by consumption of yogurt and other fermented milks. Hilton et al. (1992) found that candidal colonization and infection in women could be decreased by daily consumption of $227 \mathrm{~g}$ of yogurt containing L. acidophilus. Hata et al. (1996) found that consumption of sour milk fermented with Lactobacillus helveticus and Saccharomyces cerevisiae lowered blood pressure in elderly hypertensive patients. Yadav et al. (2007) found that consumption 
of probiotic dahi containing L. acidophilus and L. casei had antidiabetic effects in rats. Recently, Rungsri et al. (2017) found that daily consumption for 4 wk of a fermented milk containing $L$. rhamnosus SD-11 was beneficial for oral health by reducing mutans streptococci levels in saliva.

\section{SUMMARY AND FUTURE DIRECTIONS}

Manufacturing of yogurt and other cultured dairy foods has changed from crude and elementary procedures to more controlled procedures over time. A few of the advances in our knowledge that made this possible include use of ingredients in addition to milk, use of starter cultures, characterizing and sequencing the starter cultures for their improvement, and improved processing and packaging methods. A better understanding of these products has resulted in the development of a wider range of desirable products and increased opportunities for providing health benefits to consumers.

Because of improvements in the available techniques, one interesting area of future research would deal with the role that yogurt and other cultured dairy products play in the human microbiome. Escherich in 1886, as described and referenced by Kendall (1910), first published application of procedures considered modern at the time, including both aerobic and anaerobic culture methods, in investigating fecal bacteria. Many molecular biological techniques for studying these bacteria as well as the gut microbiota have since been developed. Recently, characterizing and altering the gut microbiota and metabolic alterations using these techniques have become active research topics, especially in terms of providing benefits to our health, including our mental health. Tillisch et al. (2013) showed that the activity of brain regions controlling central processing of emotion and sensation was altered in women who consumed a fermented milk product containing a probiotic for 4 wk. Also, Marin et al. (2017) was able to reduce behavioral abnormalities in mice by feeding them food pellets containing Lactobacillus reuteri ATCC 23272. Although the latter study did not specifically involve yogurt or cultured dairy products, research could be extended to incorporating microorganisms into yogurt or other cultured dairy products to see if the human microbiome can be altered in a way as to reduce behavioral abnormalities and depression in people. Many other possible health benefits resulting from altering the human microbiota with dairy products containing prebiotics or probiotics can also be investigated.

There are also many other exciting directions for future research in yogurt and other cultured dairy products.
Although yogurt and other cultured dairy products are relatively safe, additional research on pathogens, especially emerging pathogens, in these products can be expected. Further research on incorporation of additional probiotics and functional ingredients for developing value-added products can be expected. Incorporation of novel ingredients and use of novel processing and packaging technologies, possibly including clear packaging, can lead to improved products as well as a greater variety available to the consumer and with improved sustainability. Continuous improvements in yogurt and other cultured dairy products and the continued development of value-added products made possible by ongoing research as well as increased knowledge of their health benefits and additional health benefits not yet identified will increase consumer acceptability of these products as well as profits for manufacturers.

\section{ACKNOWLEDGMENTS}

Support from the Louisiana State University Agricultural Center is appreciated.

\section{REFERENCES}

Abdimoghadam, Z., E. Shamloo, A. M. Mortazavian, and M. Atefi. 2015. Frequency of Listeria species in raw milk and traditional dairy products in Isfahan, Iran. Iranian J. Nutr. Sci. Food Technol. 10:101-107.

Achanta, K., K. J. Aryana, and C. A. Boeneke. 2007. Fat-free plain set yogurts fortified with various minerals. Lebenson. Wiss. Technol. 40:424-429.

Akdeniz, H., T. Buzgan, M. Tekin, H. Karsen, and M. K. Karahocagil. 2007. An outbreak of botulism in a family in Eastern Anatolia associated with eating süzme yoghurt buried under soil. Scand. J. Infect. Dis. 39:108-114.

Akuzawa, R., and I. S. Surono. 2003. Fermented milks: Asia. Pages 1045-1049 in Encyclopedia of Dairy Sciences. Vol. 2. H. Roginski, J. W. Fuquay, and P. F. Fox, ed. Academic Press, London, UK.

Álvarez-Ordóñez, A., L. Valdés, A. Bernardo, M. Prieto, and M. López. 2013. Survival of acid adapted and non-acid adapted Salmonella Typhimurium in pasteurized orange juice and yogurt under different storage temperatures. Food Sci. Technol. Int. 19:407-414.

Amer, A. A., A. S. Aiad, and M. A. Abd-Allah. 2010. Effect of yoghurt processing and ice cream manufacture on viability of some foodborne bacteria. Assiut Vet. Med. J. 56:108-119.

Anbukkarasi, K., T. U. Maheswari, T. Hemalatha, D. K. Nanda, P. Singh, and R. Singh. 2014. Preparation of low galactose yogurt using cultures of $\mathrm{Gal}^{+}$Streptococcus thermophilus in combination with Lactobacillus delbrueckii ssp. bulgaricus. J. Food Sci. Technol. 51:2183-2189.

Anonymous. 1976. Biggest idea in yogurt since fruit. Cult. Dairy Prod. J. 11:11.

Anonymous. 1997. Resistant starch and probiotic cultures. Food Aust. 49:576-577.

Antunes, A. E. C., A. M. Liserre, E. V. Faria, K. Yotsuyanagi, and A. L. S. Lerayer. 2012. (Quantitative descriptive analysis of probiotic buttermilk.) Alimentos e Nutrição 23:619-629. [In Portuguese]

Arnott, D. R., C. L. Duitschaever, and D. H. Bullock. 1974. Microbiological evaluation of yogurt produced commercially in Ontario. J. Milk Food Technol. 37:11-13.

Aryana, K. J. 2003. Folic acid fortified fat-free plain set yoghurt. Int. J. Dairy Technol. 56:219-222. 
Aryana, K. J., H. T. Barnes, T. K. Emmick, P. McGrew, and B. Moser. 2006. Lutein is stable in strawberry yogurt and does not affect its characteristics. J. Food Sci. 71:S467-S472.

Attaie, R., P. J. Whalen, K. M. Shahani, and M. A. Amer. 1987. Inhibition of growth of Staphylococcus aureus during production of acidophilus yogurt. J. Food Prot. 50:224-228.

Ayebo, A. D., K. M. Shahani, and R. Dam. 1981. Antitumor component(s) of yogurt: Fractionation. J. Dairy Sci. 64:2318-2323.

Aytaç, S. A., and Z. Y. Özbas. 1994. Survey of the growth and survival of Yersinia enterocolitica and Aeromonas hydrophila in yogurt. Milchwissenschaft 49:322-325.

Babel, F. 1967. Techniques for cultured products. J. Dairy Sci. 50:431433.

Babel, F. J., and B. W. Hammer. 1944. Action of butter cultures in butter: A review. J. Dairy Sci. 27:79-141.

Badings, H. T., and T. E. Galesloot. 1962. Studies on the flavour of different types of butter starters with reference to the defect "yogurt flavour" in butter. Pages 199-208 in Proc. 16th Int. Dairy Congr., Vol. B, Copenhagen, Denmark. Andelsbogtrykkeriet i Odense, Odense, Denmark.

Baer, D. 1970. Lactase deficiency and yogurt. Soc. Biol. 17:143

Baker, D. B., inventor. 1983. Preparation of a low calorie, low fat fruit-containing yogurt. The Pro-Mark Companies, assignee. US Pat. No. 4,410,549.

Bayless, T. M., and S.-S. Huang. 1969. Inadequate intestinal digestion of lactose. Am. J. Clin. Nutr. 22:250-256.

Berrada, N., J.-F. Lemeland, G. Laroche, P. Thouvenot, and M. Piaia. 1991. Bifidobacterium from fermented milks: Survival during gastric transit. J. Dairy Sci. 74:409-413.

Blomqvist, T., H. Steinmoen, and L. S. Håvarstein. 2010. A food-grade site-directed mutagenesis system for Streptococcus thermophilus LMG 18311. Lett. Appl. Microbiol. 50:314-319.

Bolotin, A., B. Quinquis, P. Renault, A. Sorokin, S. D. Ehrlich, S. Kulakauskas, A. Lapidus, E. Goltsman, M. Mazur, G. D. Pusch, M. Fonstein, R. Overbeek, N. Kyprides, B. Purnelle, D. Prozzi, K. Ngui, D. Masuy, F. Hancy, S. Burteau, M. Boutry, J. Delcour, A Goffeau, and P. Hols. 2004. Complete sequence and comparative genome analysis of the dairy bacterium Streptococcus thermophilus. Nat. Biotechnol. 22:1554-1558.

Bong, D. D., and C. I. Moraru. 2014. Use of micellar casein concentrate for Greek-style yogurt manufacturing: Effects on processing and product properties. J. Dairy Sci. 97:1259-1269.

Briggs, M. 1953. An improved medium for lactobacilli. J. Dairy Res. 20:36-40.

Cassell, D. 2014. 2014 Flavor trends: Yogurt's fruitful union. http:// www.foodprocessing.com/articles/2014/flavor-trends-yogurt/.

Cayuela, C., N. Dugas, and E. Postaire, inventors. 2007. Selection and uses of lactic acid bacteria strains modulating non-specific immunity. Compagnie Gervais Danone, assignee. US Pat. No. 7,183,108 B1.

Cebeci, A., and G. C. Gürakan. 2008. Molecular methods for identification of Lactobacillus delbrueckii ssp. bulgaricus and Streptococcus thermophilus using methionine biosynthesis and 16S rRNA genes. J. Dairy Res. 75:392-398.

Centers for Disease Control and Prevention. 2011. Notes from the field: Yersinia enterocolitica infections associated with pasteurized milk - - - Southwestern Pennsylvania, March-August, 2011. MMWR Morb. Mortal. Wkly. Rep. 60:1428

Cerning, J., C. Bouillanne, M. J. Desmazeaud, and M. Landon. 1986. Isolation and characterization of exocellular polysaccharide produced by Lactobacillus bulgaricus. Biotechnol. Lett. 8:625-628.

Cerning, J., C. Bouillanne, M. J. Desmazeaud, and M. Landon. 1988. Exocellular polysaccharide production by Streptococcus thermophilus. Biotechnol. Lett. 10:255-260.

CFR (Code of Federal Regulations). 2017a. 21CFR131.200: Yogurt Accessed Feb. 7, 2017. https://www.accessdata.fda.gov/scripts/ cdrh/cfdocs/cfcfr/CFRSearch.cfm?fr=131.200.

CFR (Code of Federal Regulations). 2017b. 21CFR131.203: Lowfat yogurt. Accessed Feb. 7, 2017. https://www.accessdata.fda.gov/ scripts/cdrh/cfdocs/cfcfr/CFRSearch.cfm?fr=131.203.
CFR (Code of Federal Regulations). 2017c. 21CFR131.206: Nonfat yogurt. Accessed Feb. 7, 2017. https://www.accessdata.fda.gov/ scripts/cdrh/cfdocs/cfcfr/CFRSearch.cfm?fr=131.206.

CFR (Code of Federal Regulations). 2017d. 21CFR131.160: Sour cream. Accessed Feb. 7, 2017. https://www.accessdata.fda.gov/ scripts/cdrh/cfdocs/cfcfr/CFRSearch.cfm?fr $=131.160$.

CFR (Code of Federal Regulations). 2017e. 21CFR131.162: Acidified sour cream. Accessed Feb. 7, 2017. https://www.accessdata.fda .gov/scripts/cdrh/cfdocs/cfcfr/CFRSearch.cfm?fr=131.162.

CFR (Code of Federal Regulations). 2017f. 21CFR131.112: Cultured milk. Accessed Feb. 7, 2017. https://www.accessdata.fda.gov/ scripts/cdrh/cfdocs/cfcfr/CFRSearch.cfm?fr=131.112.

Chandan, R. C. 2006. History and consumption trends. Pages 3-15 in Manufacturing Yogurt and Fermented Milks. R. C. Chandan, C. H. White, A. Kilara, and Y. H. Hui, ed., Blackwell Publishing, Ames, IA.

Chandan, R. C., J. F. Gordon, and D. A. Walker. 1969. Dairy fermentation processes. Process Biochem. 4:13-22.

Chandan, R. C., and K. R. O'Rell. 2006. Ingredients for yogurt manufacture. Pages 179-193 in Manufacturing Yogurt and Fermented Milks. R. C. Chandan, C. H. White, A. Kilara, and Y. H. Hui, ed. Blackwell Publishing, Ames, IA.

Chapman, H. R., V. E. Bines, F. A. Glover, and P. J. Skudder. 1974. Use of milk concentrated by ultrafiltration for making hard cheese, soft cheese and yoghurt. J. Soc. Dairy Technol. 27:151-155.

Cheplin, H. A., and L. F. Rettger. 1920a. Studies on the transformation of the intestinal flora, with special reference to the implantation of bacillus acidophilus, I. Feeding experiments with albino rats. Proc. Natl. Acad. Sci. USA 6:423-426.

Cheplin, H. A., and L. F. Rettger. 1920b. Studies on the transformation of the intestinal flora, with special reference to the implantation of bacillus acidophilus, II. Feeding experiments on man. Proc. Natl. Acad. Sci. USA 6:704-705.

Choi, H. K., M. M. Schaack, and E. H. Marth. 1988. Survival of Listeria monocytogenes in cultured buttermilk and yogurt. Milchwissenschaft 43:790-792

Choi, H. S., and F. V. Kosikowski. 1985. Sweetened plain and flavored carbonated yogurt beverages. J. Dairy Sci. 68:613-619.

Chollet, M., D. Gille, A. Schmid, B. Walther, and P. Piccinali. 2013. Acceptance of sugar reduction in flavored yogurt. J. Dairy Sci 96:5501-5511.

Christensen, V. W. 1969. Concentrated dairy cultures. Food Eng. 41:104-105., 107

Ciron, C. I. E., V. L. Gee, A. L. Kelly, and M. A. E. Auty. 2012. Modifying the microstructure of low-fat yoghurt by microfluidisation of milk at different pressures to enhance rheological and sensory properties. Food Chem. 130:510-519.

Coggins, P. C., M. W. Schilling, S. Kumari, and P. D. Gerrard. 2008. Development of a sensory lexicon for conventional milk yogurt in the United States. J. Sens. Stud. 23:671-687.

Conick, H. 2016. Drinkable yogurt global market to grow by $\$ 13 \mathrm{bn}$ over next four years. Accessed Jul. 7, 2017. http://www.dairyreporter .com/Markets/Drinkable-yogurt-global-market-to-grow-by-13bn.

Conn, H. W. 1889. Bacteria in milk, cream and butter. Pages 52-67. Second Annual Report of the Storrs School Agricultural Experiment Station, Storrs, CT. Pelton \& King, Printers and Bookbinders, Middletown, CT.

Conway, P. L., S. L. Gorbach, and B. R. Goldin. 1987. Survival of lactic acid bacteria in the human stomach and adhesion to intestinal cells. J. Dairy Sci. 70:1-12.

Corbin, E. A., Jr., and J. E. Long. inventors. 1967. Process of making buttermilk by direct acidification. Nopco Chemical Co., assignee. US Pat. No. 3,340,066.

Cox, T., C. Frazier, J. Tuttle, S. Flood, L. Yagi, C. T. Yamashiro, R. Behari, C. Paszko, and R. J. Cano. 1998. Rapid detection of Listeria monocytogenes in dairy samples utilizing a PCR-based fluorogenic $5^{\prime}$ nuclease assay. J. Ind. Microbiol. Biotechnol. 21:167-174.

Crawford, R. J. M. 1962. How to succeed with yoghurt. Dairy Eng. Find 79:4-10

Cueva, O., and K. J. Aryana. 2008. Quality attributes of a heart healthy yogurt. Lebenson. Wiss. Technol. 41:537-544. 
Dan, T., D. Wang, R. L. Jin, H. P. Zhang, T. T. Zhou, and T. S. Sun. 2017. Characterization of volatile compounds in fermented milk using solid-phase microextraction methods coupled with gas chromatography-mass spectrometry. J. Dairy Sci. 100:2488-2500.

Dannenberg, F., and H.-G. Kessler. 1988a. Application of reaction kinetics to the denaturation of whey proteins in heated milk. Milchwissenschaft 43:3-7.

Dannenberg, F., and H.-G. Kessler. 1988b. Effect of denaturation of $\beta$-lactoglobulin on texture properties of set-style nonfat yoghurt. 1. Syneresis. Milchwissenschaft 43:632-635.

Dannenberg. F., and H.-G. Kessler. 1988c. Effect of denaturation of $\beta$-lactoglobulin on texture properties of set-style nonfat yoghurt. 2. Firmness and flow properties. Milchwissenschaft 43:700-704.

Dave, R. I., and N. P. Shah. 1996. Evaluation of media for selective enumeration of Streptococcus thermophilus, Lactobacillus delbrueckii ssp. bulgaricus, Lactobacillus acidophilus, and Bifidobacteria. J. Dairy Sci. 79:1529-1536.

Davies, F. L., P. A. Shankar, and H. M. Underwood. 1977. The use of milk concentrated by reverse osmosis for the manufacture of yoghurt. J. Soc. Dairy Technol. 30:23-28.

Davis, J. G. 1935. The use of special litmus milk media for the diagnostic culture of lactic acid bacteria: (1) Dextrose litmus milk, (2) Yeast extract litmus milk, and (3) Yeast extract dextrose litmus milk. J. Dairy Res. 6:121-124.

Davis, J. G. 1956. Yoghurt and other cultured milks. J. Soc. Dairy Technol. 9:69-74.

Davis, J. G. 1973. Yoghourt manufacture. Food Manuf. 48:23, 25, 27, $28,30,73$.

de Ancos, B., M. P. Cano, and R. Gómez. 2000. Characteristics of stirred low-fat yoghurt as affected by high pressure. Int. Dairy J. 10:105-111.

de Man, J. C., M. Rogosa, and M. E. Sharpe. 1960. A medium for the cultivation of lactobacilli. J. Appl. Bacteriol. 23:130-135.

de Oliveira Otto, M. C., D. Mozaffarian, D. Kromhout, A. G. Bertoni, C. T. Sibley, D. R. Jacobs Jr., and J. A. Nettleton. 2012. Dietary intake of saturated fat by food source and incident cardiovascular disease: The Multi-Ethnic Study of Atherosclerosis. Am. J. Clin. Nutr. 96:397-404.

Deane, D. D., F. E. Nelson, F. C. Ryser, and P. H. Carr. 1953. Streptococcus thermophilus bacteriophage from Swiss cheese whey. J. Dairy Sci. 36:185-191.

DeGrolier, A. 1939. (Tubercle bacilli in milk and milk products in Paris). Ann. Inst. Pasteur (Paris) 63:145-158. [In French]

Desai, N. T., L. Shepard, and M. A. Drake. 2013. Sensory properties and drivers of liking for Greek yogurts. J. Dairy Sci. 96:7454-7466.

Dineen, S. S., K. Takeuchi, J. E. Soudah, and K. J. Boor. 1998. Persistance of Escherichia coli O157:H7 in dairy fermentation systems. J. Food Prot. 61:1602-1608.

Doan, F. J., and C. D. Dahle. 1928. The manufacturing process for commercial sour cream. Bulletin 233. The Pennsylvania State College School of Agriculture and Experiment Station, State College.

Dönmez, Ö., B. A. Mogol, and V. Gökmen. 2017. Syneresis and rheological behaviors of set yogurt containing green tea and green coffee powders. J. Dairy Sci. 100:901-907.

Duthie, A. H., K. M. Nilson, H. V. Atherton, and L. D. Garrett. 1977. Proposed score card for yogurt. Cult. Dairy Prod. J. 12:10-12.

Egli, F., and F. Egli, inventors. 1980. Production of sterile yoghurt. Zentralschweizerischer Milchverbrand, assignee. US Pat. No. $4,235,934$.

Ejtahed, H. S., J. Mohtadi-Nia, A. Homayouni-Rad, M. Niafar, M. Asghari-Jafarabadi, V. Mofid, and A. Akbarian-Moghari. 2011. Effect of probiotic yogurt containing Lactobacillus acidophilus and Bifidobacterium lactis on lipid profile in individuals with type 2 diabetes mellitus. J. Dairy Sci. 94:3288-3294.

Elli, M., M. L. Callegari, S. Ferrari, E. Bessi, D. Cattivelli, S. Soldi, L. Morelli, N. G. Feuillerat, and J.-M. Antoine. 2006. Survival of yogurt bacteria in the human gut. Appl. Environ. Microbiol. 72:5113-5117

Elliker, P. R., A. W. Anderson, and G. Hannesson. 1956. An agar culture medium for lactic acid streptococci and lactobacilli. J. Dairy Sci. 39:1611-1612.
Emanuiloff, I. 1941. (Viability of Salmonella bacteria in meat and milk products). Yearb. Vet. Med. Fac. Sofia 17:591-606.

Engel, W. G. 1973. The use of lactase to sweeten yogurt without increasing calories. Cult. Dairy Prod. J. 8:6-7.

Estrada, J. D., C. Boeneke, P. Bechtel, and S. Sathivel. 2011. Developing a strawberry yogurt fortified with marine fish oil. J. Dairy Sci. 94:5760-5769.

Evans, M. R., R. L. Salmon, L. Nehaul, S. Mably, L. Wafford, M. Z. Nolan-Farrell, D. Gardner, and C. D. Ribeiro. 1999. An outbreak of Salmonella typhimurium DT170 associated with kebab meat and yoghurt relish. Epidemiol. Infect. 122:377-383.

Evrendilek, G. A., and V. M. Balasubramaniam. 2011. Inactivation of Listeria monocytogenes and Listeria innocua in yogurt drink applying combination of high pressure processing and mint essential oils. Food Contr. 22:1435-1441.

FAO/WHO. 2002. Guidelines for the evaluation of probiotics in food. Joint FAO/WHO working group report on drafting guidelines for the evaluation of probiotics in food. Accessed Mar. 30, 2017. ftp:// ftp.fao.org/es/esn/food/wgreport2.pdf.

Farrow, J. A. E., and M. D. Collins. 1984. DNA base composition, DNA-DNA homology and long-chain fatty acid studies on Streptococcus thermophilus and Streptococcus salivarius. J. Gen. Microbiol. 130:357-362.

Fayed, A. E., G. A. M. Hussein, and A. M. Farahat. 2006. Production of probiotic low-calorie sour cream. Arab Univ. J. Agric. Sci. 14:697-710.

Fernández-García, E., J. U. McGregor, and S. Traylor. 1998. The addition of oat fiber and natural alternative sweeteners in the manufacture of plain yogurt. J. Dairy Sci. 81:655-663.

Fijan, S. 2014. Microorganisms with claimed probiotic properties: An overview of recent literature. Int. J. Environ. Res. Public Health 11:4745-4767.

Finkelstein, R. 1917. A study of some factors concerned in the preparation of milk fermented with B. bulgaricus and Bact. lactis acidi. J. Dairy Sci. 1:250-258.

Fleming, D. W., S. L. Cochi, K. L. MacDonald, J. Brondum, P. S. Hayes, B. D. Plikaytis, M. B. Holmes, A. Audurier, C. V. Broome, and A. L. Reingold. 1985. Pasteurized milk as a vehicle of infection in an outbreak of listeriosis. N. Engl. J. Med. 312:404-407.

Forguson, E. A., Jr. inventor. 1963. Instant yoghurt. E. A. Forguson Jr., assignee. US Pat. 3,080,236.

Forster, K. A. 1931. (The vitamin content of the sour milk products, yoghurt, kefir and saya.). Biochem. Z. 236:276-297. [In German]

Frede, E. 2003. Butter-The product and its manufacture. Pages 220 227 in Encyclopedia of Dairy Sciences. Volume 1. H. Roginski, J. W. Fuquay, and P. F. Fox. Academic Press, London, UK.

Galesloot, T. E. 1958. [Investigations concerning the consistency of yoghurt]. Nederlandsch Melk- en Zuiveltijdschrift 12:130-165.

Galesloot, T. E., and F. Hassing. 1968. Manufacture of stirred yoghurt of high viscosity. Voed. Tech. 2:446-448. [In Dutch]

Gassem, M. A., and J. F. Frank. 1991. Physical properties of yogurt made from milk treated with proteolytic enzymes. J. Dairy Sci. $74: 1503-1511$

Ghoniem, N. A. M. 1971. The viability of some Salmonella strains and their $\mathrm{pH}$ values in Egyptian yoghurt during different storage temperatures. Milchwissenschaft 26:418-420.

Gilliland, S. E. 1989. Acidophilus milk products: A review of potential benefits to consumers. J. Dairy Sci. 72:2483-2494.

Gilliland, S. E., and M. L. Speck. 1977. Instability of Lactobacillus acidophilus in yogurt. J. Dairy Sci. 60:1394-1398.

Goodenough, E. R., and D. H. Kleyn. 1976. Influence of viable yogurt microflora on digestion of lactose by the rat. J. Dairy Sci. 59:601-606.

Gorbach, S. L., and B. R. Goldin, inventors. 1989. Lactobacillus strains and methods of selection. New England Medical Center Hospitals Inc., assignee. US Pat. No. 4,839,281.

Gray, M. L., and A. H. Killinger. 1966. Listeria monocytogenes and listeric infections. Bacteriol. Rev. 30:309-382.

Grigorov, H. 1966a. Effect of various types of heat processing of cow's milk on the duration of the coagulation process and on the $\mathrm{pH}$ and acidometric titration values of Bulgarian sour milk (yoghurt). 
Pages 643-647 in Proc. XVII Int. Dairy Congress, Section F5. Munich, Germany. Verlag Th. Mann GmbH, Hildesheim, Germany.

Grigorov, H. 1966b. Effect of heat treatment of cow's milk on the hydrophilic properties of the protein in Bulgarian yoghurt. Pages 649-654 in Proc. XVII Int. Dairy Congress, Section F5. Munich, Germany. Verlag Th. Mann GmbH, Hildesheim, Germany.

Guthrie, E. S. 1935. The Vogt method of manufacturing flake buttermilk. J. Dairy Sci. 18:139-140.

Hall, T. A. 1975. Yogurt formulations with attention to stabilizer systems. Cult. Dairy Prod. J. 10:12-14.

Hamdan, I. Y., J. E. Kunsman Jr., and D. D. Deane. 1971. Acetaldehyde production by combined yogurt cultures. J. Dairy Sci. 54:1080-1082.

Hammer, B. W., and F. J. Babel. 1943. Bacteriology of butter cultures: A review. J. Dairy Sci. 26:83-168.

Haque, A., R. K. Richardson, and E. R. Morris. 2001. Effect of fermentation temperature on the rheology of set and stirred yogurt. Food Hydrocoll. 15:593-602.

Harper, S. J., D. L. Barnes, F. W. Bodyfelt, and M. R. McDaniel. 1991. Sensory ratings of commercial plain yogurts by consumer and descriptive panels. J. Dairy Sci. 74:2927-2935.

Harper, W. J. 1968. Cultured products flavor-With emphasis on biological factors. Cult. Dairy Prod. J. 3:3-8.

Harte, F., L. Luedecke, B. Swanson, and G. V. Barbosa-Cánovas. 2003. Low-fat set yogurt made from milk subjected to combinations of high hydrostatic pressure and thermal processing. J. Dairy Sci. 86:1074-1082.

Harwalkar, V. R., and M. Kalab. 1983. Susceptibility of yoghurt to syneresis. Comparison of centrifugation and drainage methods. Milchwissenschaft 38:517-522.

Hassan, A. N., J. F. Frank, M. A. Farmer, K. A. Schmidt, and S. I. Shalabi. 1995. Formation of yogurt microstructure and threedimensional visualization as determined by confocal scanning laser microscopy. J. Dairy Sci. 78:2629-2636.

Hata, Y., M. Yamamoto, M. Ohni, K. Nakajima, Y. Nakamura, and T. Takano. 1996. A placebo-controlled study of the effect of sour milk on blood pressure in hypertensive subjects. Am. J. Clin. Nutr. 64:767-771

Hatakka, K., E. Savilahti, A. Pönkä, J. H. Meurman, T. Poussa, L. Näse, M. Saxelin, and R. Korpela. 2001. Effect of long term consumption of probiotic milk on infections in children attending day care centres: Double blind, randomised trial. BMJ 322:1327.

Heertje, I., J. Visser, and P. Smits. 1985. Structure formation in acid milk gels. Food Microstruct. 4:267-277.

Heineman, P. G. 1921. Milk. W. B. Saunders Company, Philadelphia, PA.

Heinemann, P. G., and M. Hefferan. 1909. A study of Bacillus bulgaricus. J. Infect. Dis. 6:304-318.

Hekmat, S., and D. J. McMahon. 1997. Manufacture and quality of iron-fortified yogurt. J. Dairy Sci. 80:3114-3122.

Hekmat, S., and G. Reid. 2006. Sensory properties of probiotic yogurt is comparable to standard yogurt. Nutr. Res. 26:163-166.

Hekmat, S., H. Soltani, and G. Reid. 2009. Growth and survival of Lactobacillus reuteri $\mathrm{RC}-14$ and Lactobacillus rhamnosus GR-1 in yogurt for use as a functional food. Innov. Food Sci. Emerg. Technol. 10:293-296.

Hempenius, W. L., B. J. Liska, and R. B. Harrington. 1969. Taste panel studies of flavor levels in sour cream. J. Dairy Sci. 52:588-593.

Hernandez, K., and Y. W. Park. 2014. Evaluation of 20 macro and trace mineral concentrations in commercial goat milk yogurt and its cow milk counterpart. Food Nutr. Sci. 5:889-895.

Herter, C. A., and A. I. Kendall. 1908. An observation on the fate of $B$. bulgaricus (in bacillac) in the digestive tract of a monkey. J. Biol. Chem. 5:293-302.

Hertzler, S. R., and S. M. Clancy. 2003. Kefir improves lactose digestion and tolerance in adults with lactose maldigestion. J. Am. Diet. Assoc. 103:582-587.

Hervert, C. J., N. H. Martin, K. J. Boor, and M. Wiedmann. 2017. Survival and detection of coliforms, Enterobacteriaceae, and gramnegative bacteria in Greek yogurt. J. Dairy Sci. 100:950-960.
Hildreth, E. A., S. M. Mellinkoff, G. W. Blair, and D. M. Hildreth. 1951. The effect of vegetable fat ingestion on human serum cholesterol concentration. Circulation 3:641-646.

Hilker, L. D. 1947. A method for measuring the body of cultured cream. J. Dairy Sci. 30:161-164.

Hill, C., B. O'Driscoll, and I. Booth. 1995. Acid adaptation and food poisoning microorganisms. Int. J. Food Microbiol. 28:245-254.

Hilton, E., H. D. Isenberg, P. Alperstein, K. France, and M. T. Borenstein. 1992. Ingestion of yogurt containing Lactobacillus acidophilus as prophylaxis for candidal vaginitis. Ann. Intern. Med. 116:353-357.

Horton, B. S., R. L. Goldsmith, and R. R. Zall. 1972. Membrane processing of cheese whey reaches commercial scale. Food Technol. $26: 30-32,34-35$.

Hoyda, D. L., P. J. Streiff, and E. Epstein, inventors. 1990. Method of making fiber enriched yogurt. Borden Inc., assignee. US Pat. No. $4,971,810$.

Hudson, L. M., J. Chen, A. R. Hill, and M. W. Griffiths. 1997. Bioluminiscence: A rapid indicator of Escherichia coli $\mathrm{O} 157: \mathrm{H} 7$ in selected yoghurt and cheese varieties. J. Food Prot. 60:891-897.

Hull, R. R., A. V. Roberts, and J. J. Mayes. 1984. Survival of Lactobacillus acidophilus in yoghurt. Aust. J. Dairy Technol. 39:164-166.

Hume, M. E. 2011. Historic perspective: Prebiotics, probiotics, and other alternatives to antibiotics. Poult. Sci. 90:2663-2669.

Humphreys, C. L., and M. Plunkett. 1969. Yoghurt: A review of its manufacture. Dairy Sci. Abstr. 31:607-622.

Hyvönen, L., and M. Slotte. 1983. Alternative sweetening of yoghurt. J. Food Technol. 18:97-112

IDFA (International Dairy Foods Association). 2017. Dairy Facts 2016 Edition. IDFA, Washington, DC.

Igoe, R. S., inventor. 1979. Direct acidified yogurt. Merck \& Co. Inc., assignee. US Pat. No. 4,169,854.

Ikonomov, L., and D. Todorov. 1964. (Studies of the viability of Listeria monocytogenes in ewes' milk and dairy products). Vet. Med. Nauki 1:23-29. [In Bulgarian]

Ilic, D. B., and S. H. Ashoor. 1988. Stability of vitamins A and C in fortified yogurt. J. Dairy Sci. 71:1492-1498.

Illupapalayam, V. V., S. C. Smith, and S. Gamlath. 2014. Consumer acceptability and antioxidant potential of probiotic-yogurt with spices. Lebensm. Wiss. Technol. 55:255-262.

Jagielski, V. A., inventor. 1871. Improvement in dietetic compounds from milk. US Pat. No. 117,889.

Jankov, J., and I. V. Stoyanov. 1966. Study on the thermophilic lactobacilli in milk for yoghurt production. Pages 677-680 in Proc. XVII Int. Dairy Congr., Section F5. Munich, Germany. Verlag Th. Mann GmbH, Hildesheim, Germany.

Jenness, R., and S. Patton. 1959. Principles of Dairy Chemistry. John Wiley \& Sons Inc., New York, NY.

Jepsen, S. 1979. Membrane filtration in the manufacture of cultured milk products yogurt, Cottage cheese. Cult. Dairy Prod. J. 14:5-8.

Jespersen, N. J. T. 1977. The use of commercially available concentrated starters. Paper (b). J. Soc. Dairy Technol. 30:47-51.

Jones, E. E., R. J. Kim-Farley, M. Algunaid, M. A. Parvez, Y. A. Ballad, A. W. Hightower, W. A. Orenstein, and C. V. Broome. 1985. Diphtheria: A posible foodborne outbreak in Hodeida, Yemen Arab Republic. Bull. World Health Organ. 63:287-293.

Kaila, M., E. Isolauri, E. Soppi, E. Virtanen, S. Laine, and H. Arvilommi. 1992. Enhancement of the circulating antibody secreting cell response in human diarrhea by a human Lactobacillus strain. Pediatr. Res. 32:141-144.

Kalab, M., D. B. Emmons, and A. G. Sargant. 1975. Milk-gel structure. IV. Microstructure of yoghurts in relation to the presence of thickening agents. J. Dairy Res. 42:453-458.

Karlin, R. 1961. (Vitamin $\mathrm{B}_{12}$ formation in fermented milks and possibilities of increasing the concentration by adding Propionibacterium shermanii to the microbial cultures). Ann. Nutr. Aliment. 15:247-256. [In French]

Kazmi, S. A., R. Vieth, and D. Rousseau. 2007. Vitamin $\mathrm{D}_{3}$ fortification and quantification in processed dairy products. Int. Dairy J $17: 753-759$. 
Keating, K. R., and C. H. White. 1990. Effect of alternative sweeteners in plain and fruit-flavored yogurts. J. Dairy Sci. 73:54-62.

Keenan, T. W., F. W. Bodyfelt, and R. C. Lindsay. 1968. Quality of commercial buttermilks. J. Dairy Sci. 51:226-227.

Kendall, A. I. 1910. Observations on aciduric (acidophilic) bacteria. J. Med. Res. 22:153-167.

Kennedy, S. 2016. The cultured dairy category is getting a whole lot bolder. Dairy Foods 117:36-38, 40.

Kerr, K. G., N. A. Rotowa, and P. M. Hawkey. 1992. Listeria in yoghurt? J. Nutr. Med. 3:27-29.

Kim, H. S., and S. E. Gilliland. 1983. Lactobacillus acidophilus as a dietary adjunct for milk to aid lactose digestion in humans. J. Dairy Sci. 66:959-966.

Knudsen, S. 1931. Starters. J. Dairy Res. 2:137-163.

Kolakowski, P., and K. Pawlikowska. 2012. Kefir as a probiotic delivery vehicle. Milchwissenschaft 67:159-162.

Kolars, J. C., M. D. Levitt, M. Aouji, and D. A. Savaiano. 1984 Yogurt-An autodigesting source of lactose. N. Engl. J. Med. 310:1-3.

Kosikowski, F. V. 1969. Flavored buttermilks. J. Dairy Sci. 52:799800.

Kosikowski, F. V., and V. V. Mistry. 1997. Cheese and Fermented Milk Foods, Vol. 2, Procedures and Analysis. 3rd ed. F. V. Kosikowski LLC, Great Falls, VA.

Kroger, M. 1975. How do you want your yoghurt, with or without bacteria? A review of the controversy. Cult. Dairy Prod. J. 10:18-22.

Kroger, M., and J. C. Weaver. 1973. Confusion about yogurt-Compositional and otherwise. J. Milk Food Technol. 36:388-391.

Kulp, W. L. 1927. An agar medium for plating L. acidophilus and $L$. bulgaricus. Science 66:512-513.

Kulp, W. L., and L. F. Rettger. 1924. Comparative study of Lactobacillus acidophilus and Lactobacillus bulgaricus. J. Bacteriol. 9:357-395.

Lawrence, R. L., and G. A. Perry, inventors. 1962. Process for improving the flavor of cultured milk products and the resulting product. Corn Products Company, assignee. US Pat. No. 3,022,176.

Lee, H., B. A. Friend, and K. M. Shahani. 1988. Factors affecting the protein quality of yogurt and acidophilus milk. J. Dairy Sci. 71:3203-3213

Lee, S. C., R. B. Billmyre, A. Li, S. Carson, S. M. Sykes, E. Y. Huh, P. Mieczkowski, D. C. Ko, C. A. Cuomo, and J. Heitman. 2014 Analysis of a food-borne fungal pathogen outbreak: Virulence and genome of a Mucor circinelloides isolate from yogurt. MBio 5:e01390-14.

Lee, W. J., and J. A. Lucey. 2004. Structure and physical properties of yogurt gels: Effect of inoculation rate and incubation temperature. J. Dairy Sci. 87:3153-3164.

Leeds, A. R. 1888. Report of the dairy commissioner of the state of New Jersey, 1887, pages 37-47. The John L. Murphy Pub. Co. Printers, Trenton, N. J.

Lick, S., M. Keller, W. Bockelmann, and K. J. Heller. 1996. Rapid identification of Streptococcus thermophilus by primer-specific PCR amplification based on its lacZ gene. Syst. Appl. Microbiol. 19:74-77.

Lick, S., and M. Teuber. 1992. Construction of a species-specific DNA oligonucleotide probe for Streptococcus thermophilus on the basis of a chromosomal lacZ gene. Syst. Appl. Microbiol. 15:456-459.

Lilly, D. M., and R. H. Stillwell. 1965. Probiotics: Growth-promoting factors produced by microorganisms. Science 147:747-748.

Linares, D. M., T. F. O'Callaghan, P. M. O'Connor, R. P. Ross, and C. Stanton. 2016. Streptococcus thermophilus APC151 strain is suitable for the manufacture of naturally GABA-enriched bioactive yogurt. Front. Microbiol. 7:1876. https://doi.org/10.3389/fmicb .2016 .01876

Lindsay, R. C., E. A. Day, and W. E. Sandine. 1965a. Green flavor defect in lactic starter cultures. J. Dairy Sci. 48:863-869.

Lindsay, R. C., E. A. Day, and W. E. Sandine. 1965b. Identification of volatile flavor components of butter culture. J. Dairy Sci. 48:15661574

Linnan, M. J., L. Mascola, X. D. Lou, V. Goulet, S. May, C. Salminen, D. W. Hlird, M. L. Yonekura, P. Hayes, R. Weawer, A. Audurier,
B. D. Plikaytis, S. L. Fannin, A. Kleks, and C. V. Broome. 1988 Epidemic listeriosis associated with Mexican-style cheese. N. Engl. J. Med. 319:823-828.

Lister, J. 1873. Further contribution to the natural history of bacteria and the germ theory of fermentative changes. Q. J. Microsc. Sci. 13:380-408.

Lister, J. 1878. On the lactic fermentation, and its bearings on pathology. Trans. Pathol. Soc. Lond. 29:425-467.

Little, L. 1967. Techniques for acidified dairy products. J. Dairy Sci. 50:434-440.

Lourens-Hattingh, A., and B. C. Viljoen. 2001. Yogurt as probiotic carrier food. Int. Dairy J. 11:1-17.

Lucca, L. 1975. Survival of pathogenic enterobacteria in yoghurt. Latte 232:236.

Lucey, J. A., and H. Singh. 2003. Acid coagulation of milk. Pages 1001-1025 in Advanced Dairy Chemistry, Vol. 1: Proteins, Part B. 3rd ed. P. F. Fox and P. L. H. McSweeney, ed. Kluwer Academic/ Plenum Publishers, New York, NY.

Malone, M. J., and E. A. Miles, inventors. 1984. Artificially sweetened gelled yogurt. The Coca-Cola Company, assignee. US Pat. No. $4,430,349$.

Manchester, K. L. 2007. Louis Pasteur, fermentation, and a rival. S. Afr. J. Sci. 103:377-380.

Mann, G. V. 1977. A factor in yogurt which lowers cholesteremia in man. Atherosclerosis 26:335-340.

Mann, G. V., and A. Spoerry. 1974. Studies of a surfactant and cholesteremia in the Maasai. Am. J. Clin. Nutr. 27:464-469.

Marin, I. A., J. E. Goertz, T. Ren, S. S. Rich, S. Onengut-Gumuscu, E. Farber, M. Wu, C. C. Overall, J. Kipnis, and A. Gaultier. 2017. Microbiota alteration is associated with the development of stressinduced despair behavior. Sci. Rep. 7:43859. https://doi.org/10 $.1038 /$ srep 43859

Marriott, W. M. 1919. The artificial feeding of athreptic infants. J. Am. Med. Assoc. 73:1173-1177.

Marriott, W. M., and L. T. Davidson. 1923. Acidified whole milk as a routine infant food. J. Am. Med. Assoc. 81:2007-2009.

Marteau, P., E. Cuillerier, S. Meance, M. F. Gerhardt, A. Myara, M. Bouvier, C. Bouley, F. Tondu, G. Bommelaer, and J. C. Grimaud. 2002. Bifidobacterium animalis strain DN-173 010 shortens the colonic transit time in healthy women: A double-blind, randomized, controlled study. Aliment. Pharmacol. Ther. 16:587-593.

Mater, D. D. G., L. Bretigny, O. Firmesse, M.-J. Flores, A. Mogenet, J.-L. Bresson, and G. Corthier. 2005. Streptococcus thermophilus and Lactobacillus delbrueckii ssp. bulgaricus survive gastrointestinal transit of healthy volunteers consuming yogurt. FEMS Microbiol. Lett. 250:185-187.

Matuszewski, T., E. Pijanowski, and J. Supinska. 1936. Streptococcus diacetilactis $\mathrm{n}$. sp. and its application to butter making. Pr. Zakl. Microbiol. Przem. Rosl. Warsz. 21:1-28.

Maxa, V. 1949. The decreases of vitamin C during some treatments of milk. Pages 208-213 in Proc. XIIth Int. Dairy Congr., Section II, Stockholm, Sweden. Ivar Haegsstroms, Stockholm, Sweden.

McLaughlin, C. B. 1946. A readily prepared medium for the cultivation of the lactobacilli. J. Bacteriol. 51:560-561.

Metchnikoff, E. 1908. The Prolongation of Life. G. P. Putnam's Sons, New York, NY

Metzger, J., inventor. 1962a. Vitamin C enriched yogurt. Beatrice Foods Co., assignee. US Pat. No. 3,025,164.

Metzger, J., inventor. 1962b. Yogurt containing an unsaturated vegetable fat. Beatrice Foods Co., assignee. US Pat. No. 3,025,165.

Michaelian, M. B., R. S. Farmer, and B. W. Hammer. 1933. The relationship of acetylmethylcarbinol and diacetyl to butter cultures. Research Bulletin No. 155 of the Agricultural Experiment Station, Iowa State College of Agriculture and Mechanic Arts, Ames.

Mijan, M. A., K.-H. Choi, and H.-S. Kwak. 2014. Physicochemical, microbial, and sensory properties of nanopowdered eggshell-supplemented yogurt during storage. J. Dairy Sci. 97:3273-3280.

Mocquot, G., and C. Hurel. 1970. The selection and use of some microorganisms for the manufacture of fermented and acidified milk products. J. Soc. Dairy Technol. 23:130-146. 
Modler, H. W., M. E. Larmond, C. S. Lin, D. Froehlich, and D. B. Emmons. 1983. Physical and sensory properties of yogurt stabilized with milk proteins. J. Dairy Sci. 66:422-429.

Morgan, D., C. P. Newman, D. N. Hutchinson, A. M. Walker, B. Rowe, and F. Majid. 1993. Verotoxin producing Escherichia coli O157 infections associated with the consumption of yoghurt. Epidemiol. Infect. 111:181-187.

Mozaffarian, D., T. Hao, E. B. Rimm, W. C. Willett, and F. B. Hu. 2011. Changes in diet and lifestyle and long-term weight gain in women and men. N. Engl. J. Med. 364:2392-2404.

Muhammed, W., D. Muleta, Y. Deneke, A. Gashaw, and M. Bitew. 2013. Studies on occurence of Listeria monocytogenes and other species in milk and milk products in retail market of Jimma Town, Ethiopia. Asian J. Dairy Food Res. 32:35-39.

Murray, E. G. D., R. A. Webb, and M. B. R. Swann. 1926. A disease of rabbits characterised by a large mononuclear leucocytosis, caused by a hitherto undescribed bacillus Bacterium monocytogenes (n. sp.). J. Pathol. 29:407-439.

Myers, R. P. 1931. Transformation of the intestinal flora through the feeding of unfermented acidophilus milk. Am. J. Public Health Nations Health 21:867-872.

Narayanan, P., B. Chinnasamy, L. Jin, and S. Clark. 2014. Use of justabout-right scales and penalty analysis to determine appropriate concentrations of stevia sweeteners for vanilla yogurt. J. Dairy Sci. 97:3262-3272

Nasr, S. E., N. M. Saad, E. A. Nasr, M. W. Nahed, and M. A. E. Walaa. 2014. The viability of Mycobacterium bovis in yoghurt and kareish cheese. Glob. J. Agric. Food Safety Sci. 1:261-269.

Nelson, J. A., and G. M. Trout. 1964. Judging Dairy Products. 4th ed. The Olsen Publishing Co., Milwaukee, WI.

Nicholls, L., and A. Nimalasuriya. 1939. The preparation of fermented milk ("curds"). Ceylon J. Sci. D Med. Sci. 5:17-20.

Nordsiek, F. W., inventor. 1938. Process of manufacturing culture. The Sanoderm Company Inc., assignee. US Pat. No. 2,121,442.

O'Brien, K., C. Boeneke, W. Prinyawiwatkul, J. Lisano, D. Shackelford, K. Reeves, M. Christensen, R. Hayward, K. Carabante Ordonez, and L. K. Stewart. 2017. Sensory analysis of a kefir product designed for active cancer survivors. J. Dairy Sci. 100:4349-4353.

O'Connor, E. B., E. Barrett, G. Fitzgerald, C. Hill, C. Stanton, and R. P. Ross. 2005. Production of vitamins, exopolysaccharides and bacteriocins by probiotic bacteria. Pages 167-194 in Probiotic Dairy Products. A. Y. Tamime, ed. Blackwell Publishing Ltd., Oxford, UK

O’Mahony, M., E. Mitchell, R. J. Gilbert, D. N. Hutchinson, N. T. Begg, J. C. Rodhouse, and J. E. Morris. 1990. An outbreak of foodborne botulism associated with contaminated hazelnut yoghurt. Epidemiol. Infect. 104:389-395.

O'Neil, J. M., D. H. Kleyn, and L. B. Hare. 1979. Consistency and compositional characteristics of commercial yogurts. J. Dairy Sci. 62:1032-1036.

Olson, D., and K. J. Aryana. 2017. Omega-3 polyunsaturated fatty acids added to yogurt. Pages 135-149 in Yogurt in Health and Disease Prevention. Academic Press, London, UK

Olson, D. W., and K. J. Aryana. 2008. An excessively high Lactobacillus acidophilus inoculation level in yogurt lowers product quality during storage. Lebenson. Wiss. Technol. 41:911-918.

Omara, S. T., H. A. El Fadaly, and A. M. A. Barakat. 2015. Public health hazard of zoonotic Campylobacter jejuni reference to Egyptian regional and seasonal variations. Res. J. Microbiol. 10:343354 .

Orla-Jensen, S. 1919. The Lactic Acid Bacteria. Mémoires de L'Académie Royale des Sciences et des Lettres de Danemark, Copenhagen, Denmark.

Orla-Jensen, S. 1921. Dairy Bacteriology. Translated by P. S. Arup. P. Blakiston's Son \& Co., Philadelphia, PA.

Ortiz-Rivera, Y., R. Sánchez-Vega, N. Gutiérrez-Méndez, J. LeónFélix, C. Acosta-Muñiz, and D. R. Sepulveda. 2017. Production of reuterin in a fermented milk product by Lactobacillus reuteri: Inhibition of pathogens, spoilage microorganisms, and lactic acid bacteria. J. Dairy Sci. 100:4258-4268.
Ozek, O. 1942. (Does yoghurt kill pathogenic bacteria?). Istanbul Seriyati $24: 189-195$

Ozturkoglu-Budak, S., C. Akal, and A. Yetisemiyen. 2016. Effect of dried nut fortification on functional, physicochemical, textural, and microbiological properties of yogurt. J. Dairy Sci. 99:8511-8523.

Pachekrepapol, U., J. A. Lucey, Y. Gong, R. Naran, and P. Azadi. 2017. Characterization of the chemical structures and physical properties of exopolysaccharides produced by various Streptococcus thermophilus strains. J. Dairy Sci. 100:3424-3435.

Page, R. A., and V. G. Lavalie, inventors. 1955. Sour cream dairy product. Kraft Foods Company, assignee. US Pat. No. 2,719,793.

Pala, V., S. Sieri, F. Berrino, P. Vineis, C. Sacerdote, D. Palli, G. Masala, S. Panico, A. Mattiello, R. Tumino, M. C. Giurdanella, C. Agnoli, S. Grioni, and V. Krogh. 2011. Yogurt consumption and risk of colorectal cancer in the Italian European Prospective Investigation into Cancer and Nutrition cohort. Int. J. Cancer 129:2712-2719.

Parnell-Clunies, E. M., Y. Kakuda, K. Mullen, D. R. Arnott, and J. M. deMan. 1986. Physical properties of yogurt: A comparison of vat versus continuous heating systems of milk. J. Dairy Sci. 69:2593-2603.

Parra, M. D., B. E. Martínez de Morentin, J. M. Cobo, A. Mateos, and J. A. Martínez. 2004. Daily ingestion of fermented milk containing Lactobacillus casei DN114001 improves innate defense capacity in healthy middle-aged people. J. Physiol. Biochem. 60:85-91.

Peake, S. E., and G. Stanley. 1978. Partial characterization of a bacteriophage of Lactobacillus bulgaricus isolated from yoghurt. J. Appl. Bacteriol. 44:321-323.

Pette, J. W., and J. S. Kooy. 1952. Bacteriophages in yoghurt. Nederlandsch Melk- en Zuiveltijdschrift 6:233-241.

Pette, J. W., and H. Lolkema. 1950a. Yoghurt. 1. Symbiosis and antibiosis in mixed cultures of Lactobacillus bulgaricus and Streptococcus thermophilus. Nederlandsch Melk- en Zuiveltijdschrift 4:197-208.

Pette, J. W., and H. Lolkema. 1950b. Yoghurt. 3. Acid production and aroma formation in yoghurt. Nederlandsch Melk- en Zuiveltijdschrift 4:261-273.

Pette, J. W., and H. Lolkema. 1951. Yogurt. 5. Firmness and whey separation of milk yoghurt. Nederlandsch Melk- en Zuiveltijdschrift 5:27-45.

Popa, D., and Z. Ustunol. 2011. Sensory attributes of low-fat strawberry yoghurt as influenced by honey from different floral sources, sucrose and high-fructose corn sweetener. Int. J. Dairy Technol. 64:451-454.

Radke-Mitchell, L. C., and W. E. Sandine. 1986. Influence of temperature on associative growth of Streptococcus thermophilus and Lactobacillus bulgaricus. J. Dairy Sci. 69:2558-2568.

Ram Ayyar, C. S. 1928. Microorganisms and the production of dahi. Agric. J. India 23:107-114.

Rašić, J., and Z. Milanović. 1966. Influence of Str. diacetilactisculture on the flavour of yoghurt. Pages 637-642 in Proc. XVII Int. Dairy Congr., Section F5, Munich, Germany. Verlag Th. Mann GmbH, Hildescheim, Germany.

Reddy, G. V., B. A. Friend, K. M. Shahani, and R. E. Farmer. 1983. Antitumor activity of yogurt components. J. Food Prot. 46:8-11.

Reddy, G. V., K. M. Shahani, and M. R. Banerjee. 1973. Inhibitory effect of yogurt on Ehrlich ascites tumor-cell proliferation. J. Natl. Cancer Inst. 50:815-817.

Reddy, M. S. inventor. 1989. Enhancement of Lactobacillus acidophilus growth and viability in yogurt and other cultured dairy products. Malireddy S. Reddy, assignee. US Pat. No. 4,797,289

Reis, R. C., V. P. R. Minim, H. M. A. Bolini, B. R. P. Dias, L. A. Minim, and E. B. Ceresino. 2011. Sweetness equivalence of different sweeteners in strawberry-flavored yogurt. J. Food Qual. $34: 163-170$.

Renz, U., and Z. Puhan. 1975. (Factors promoting bitterness in yoghurt). Milchwissenschaft 30:265-271. [In German]

Roberts, H. A., T. J. Claydon, and R. Bassette. 1971. Pre-acidification of milk for cultured buttermilk. Am. Dairy Rev. 33:44-46.

Robinson, R. K. 1977. A dairy product for the future-Concentrated yoghurt. S. Afr. J. Dairy Technol. 9:59-61. 
Robinson, R. K. 1995. The potential of inulin as a functional ingredient. Br. Food J. 97:30-32.

Robinson, R. K., and A. Y. Tamime. 1975. Yoghurt-A review of the product and its manufacture. J. Soc. Dairy Technol. 28:149-163.

Rodas, B. A., J. O. Angulo, J. de la Cruz, and H. S. Garcia. 2002. Preparation of probiotic buttermilk with Lactobacillus reuteri. Milchwissenschaft 57:26-28.

Rogers, L. A. 1914. The preparation of dried cultures. J. Infect. Dis. 14:100-123.

Rosell, J. M. 1933. Yoghourt milk. Can. Public Health J. 24:344-347.

Rotch, T. M., and A. I. Kendall. 1911. A preparatory study of the bacillus acidophilus in regard to its possible therapeutic use. Am. J. Dis. Child. 11:30-38.

Rowland, S. J. 1934. The heat denaturation of albumin and globulin in milk. J. Dairy Res. 5:46-53.

Rubin, H. E., and F. Vaughan. 1979. Elucidation of the inhibitory factors of yogurt against Salmonella typhimurium. J. Dairy Sci. 62:1873-1879.

Rungsri, P., N. Akkarachaneeyakorn, M. Wongsuwanlert, S. Piwat, P. Nantarakchaikul, and R. Teanpaisan. 2017. Effect of fermented milk containing Lactobacillus rhamnosus SD11 on oral microbiota of healthy volunteers: A randomized clinical trial. J. Dairy Sci. 100:7780-7787.

Ryan, J. M., C. H. White, R. H. Gough, and A. C. Burns. 1984. Consumer acceptance of fruit-flavored yogurt drinks. J. Dairy Sci. 67:1369-1375.

Saal, H., and R. J. Krebs. 1975. Flavors and ingredients survey. Am. Dairy Rev. 3:27-37.

Saffon, M., V. Richard, R. Jiménez-Flores, S. F. Gauthier, M. Britten, and Y. Pouliot. 2013. Behavior of heat-denatured whey:buttermilk protein aggregates during the yogurt-making process and their influence on set-type yogurt properties. Foods 2:444-459.

Salih, M. A., W. E. Sandine, and J. W. Ayres. 1990. Inhibitory effects of Microgard ${ }^{\mathrm{TM}}$ on yogurt and cottage cheese spoilage organisms. J. Dairy Sci. 73:887-893.

San, L. L., M. M. Win, T. Oo, T. Hla, T. T. Htwe, and M. T. Htay. 2012. A study of Bacillus cereus in milk and milk products. Myanmar Health Sci. Res. J. 24:67-71.

Sanderson, J. D. 1957. Switch to paper cups gives yogurt big boost. Food Eng. 29:80-82.

Savello, P. A., and R. A. Dargan. 1995. Improved yogurt physical properties using ultrafiltration and very-high temperature heating. Milchwissenschaft 50:86-90.

Savello, P. A., and R. A. Dargan. 1997. Reduced yogurt syneresis using ultrafiltration and very-high temperature heating. Milchwissenschaft 52:573-577.

Sayon-Orea, C., M. A. Martínez-González, M. Ruiz-Canela, and M. Bes-Rastrollo. 2017. Associations between yogurt consumption and weight gain and risk of obesity and metabolic syndrome: A systematic review. Adv. Nutr. 8:146S-154S.

Schellhaass, S. M., and H. A. Morris. 1985. Rheological and scanning electron microscopic examination of skim milk gels obtained by fermenting with ropy and non-ropy strains of lactic acid bacteria. Food Microstruct. 4:279-287.

Schleifer, K. H., J. Kraus, C. Dvorak, R. Kilpper-Bälz, M. D. Collins, and W. Fischer. 1985. Transfer of Streptococcus lactis and related streptococci to the genus Lactococcus gen. nov. Syst. Appl. Microbiol. 6:183-195

Schmidt, K., and K. Bledsoe. 1995. Effects of homogenization pressure on physical and sensory characteristics of low fat yogurt. Cult. Dairy Prod. J. 30:7-10.

Schulz, M. E. 1949. (Yogurt and yogurt cultures). Milchwissenschaft 4:206-215. (In German).

Shah, N. P., W. E. V. Lankaputhra, M. L. Britz, and W. S. A. Kyle. 1995. Survival of Lactobacillus acidophilus and Bifidobacterium bifidum in commercial yoghurt during refrigerated storage. Int. Dairy J. 5:515-521.

Shahani, K. M., J. R. Vakil, and R. C. Chandan, inventors. 1972. Antibiotic acidophilin and process of preparing the same. The University of Nebraska, assignee. US Pat. 3,689,640.
Shahani, K. M., J. R. Vakil, and A. Kilara. 1976. Natural antibiotic activity of Lactobacillus acidophilus and bulgaricus. Cult. Dairy Prod. J. 11:14-17.

Shaker, R. R., T. M. Osaili, and M. Ayyash. 2008. Effect of thermophilic lactic acid bacteria on the fate of Enterobacter sakazakii during proocessing and storage of plain yogurt. J. Food Saf. $28: 170-182$.

Shepard, L., R. E. Miracle, P. Leksrisompong, and M. A. Drake. 2013. Relating sensory and chemical properties of sour cream to consumer acceptance. J. Dairy Sci. 96:5435-5454.

Shida, K., and K. Nomoto. 2013. Probiotics as efficient immunopotentiators: Translational role in cancer prevention. Indian J. Med. Res. 138:808-814.

Shoup, M. E. 2016. Americans turn to drinkable yogurt to satify their hunger for innovation in cultured dairy. Accessed Jul. 7 , 2017. http://www.dairyreporter.com/Markets/Americans-turn-to -yogurt-drinks-to-satisfy-their-hunger-for-innovation.

Siitonen, S., H. Vapaatalo, S. Salminen, A. Gordin, M. Saxelin, R. Wikberg, and A.-L. Kirkkola. 1990. Effect of Lactobacillus GG yoghurt in prevention of antibiotic associated diarrhoea. Ann. Med. 22:57-59.

Siragusa, G. R., and M. G. Johnson. 1988. Persistence of Listeria monocytogenes in yogurt as determined by direct plating and enrichment methods. Int. J. Food Microbiol. 7:147-160.

Somkuti, G. A., and D. H. Steinberg. 1988. Genetic transformation of Streptococcus thermophilus by electroporation. Biochimie 70:579585.

Soulides, D. A. 1955. A synergism between yoghurt bacteria and yeasts and the effect of their association upon the viability of the bacteria. Appl. Microbiol. 3:129-131.

Spanhaak, S., R. Havenaar, and G. Schaafsma. 1998. The effect of consumption of milk fermented by Lactobacillus casei strain Shirota on the intestinal microflora and immune parameters in humans. Eur. J. Clin. Nutr. 52:899-907.

Stepaniak, L., and A. Fetliński. 2003. Fermented milks: Kefir. Pages 1049-1054 in Encyclopedia of Dairy Sciences. Vol. 2. H. Roginski, J. W. Fuquay, and P. F. Fox, ed. Academic Press, London, UK.

Stolk, K. 1955. The thermoresistance of some bacteriophages isolated from starters and yoghurt cultures. Nederlandsch Melk- en Zuiveltijdschrift 9:37-41.

Storch, V., inventor. 1893. Method of making butter. Christian D. A. Hansen, assignee. US Pat. No. 495,381.

Swithinbank, H., and G. Newman. 1903. Bacteriology of Milk. E. P. Dutton \& Co., New York, NY.

Szczawiński, J., M. E. Szczawińska, A. Łobacz, and A. JackowskaTracz. 2016. Modeling the effect of temperature on survival rate of Listeria monocytogenes in yogurt. Pol. J. Vet. Sci. 19:317-324.

Tamime, A. Y., and H. C. Deeth. 1980. Yogurt: Technology and biochemistry. J. Food Prot. 43:939-977.

Tamime, A. Y., A. Hassan, E. Earnworth, and T. Toba. 2007. Structure of fermented milks. Pages 134-169 in Structure of Dairy Products, A. Y. Tamime, ed. Blackwell Publishing, Oxford, UK.

Tchilinguirian, V. inventor. 1960. (Yogurt enriched with calcium). French patent 1,237,357. [In French].

Templeton, H. L., and H. H. Sommer. 1929. The use of citric acid and sodium citrate in starter cultures. J. Dairy Sci. 12:21-36.

Templeton, H. L., and H. H. Sommer. 1935. The use of citric acid and sodium citrate in buttermaking. J. Dairy Sci. 18:97-104.

Terzaghi, B. E., and W. E. Sandine. 1975. Improved medium for lactic streptococci and their bacteriophages. Appl. Microbiol. 29:807813.

Tharmaraj, N., and N. P. Shah. 2003. Selective enumeration of Lactobacillus delbrueckii ssp. bulgaricus, Streptococcus thermophilus, Lactobacillus acidophilus, Bifidobacteria, Lactobacillus casei, Lactobacillus rhamnosus, and Propionibacteria. J. Dairy Sci. 86:22882296.

Thompson, J. L., K. Lopetcharat, and M. A. Drake. 2007. Preferences for commercial strawberry drinkable yogurts among African American, Caucasian, and Hispanic consumers in the United States. J. Dairy Sci. 90:4974-4987. 
Tillisch, K., J. Labus, L. Kilpatrick, Z. Jiang, J. Stains, B. Ebrat, D. Guyonnet, S. Legrain-Raspaud, B. Trotin, B. Naliboff, and E. A. Mayer. 2013. Consumption of fermented milk product with probiotic modulates brain activity. Gastroenterology 144:1394-1401.

Tirloni, E., C. Bernardi, F. Colombo, and S. Stella. 2015. Microbiological shelf life at different temperatures and fate of Listeria monocytogenes and Escherichia coli inoculated in unflavored and strawberry yogurts. J. Dairy Sci. 98:4318-4327.

Todd, E. C. D. 1978. Foodborne disease in Canada-1975 annual summary. J. Food Prot. 41:910-918.

Todoric, R., and K. Savadinovic. 1973. Use of dried whey in yoghurt manufacture and its effect on acidity and consistency. Mljekarstvo 23:78-86.

Todorov, D. 1967. (Changes in Salmonella under the influence of lactic acid bacteria in milk and milk products). Congr. Bulg. Microbiol. 625-630. [in Bulgarian].

Trachoo, N., and V. V. Mistry. 1998. Application of ultrafiltered sweet buttermilk and sweet buttermilk poder in the manufacture of nonfat and low fat yogurts. J. Dairy Sci. 81:3163-3171.

Turchet, P., M. Laurenzano, S. Auboiron, and J. M. Antoine. 2003. Effect of fermented milk containing the probiotic Lactobacillus casei DN-114001 on winter infections in free-living elderly subjects: A randomised, controlled pilot study. J. Nutr. Health Aging 7:75-77.

Ubeyratne, J. K. H., M. D. N. Jayaweera, and K. H. D. T. Kasagala. 2014. Prevalence of Listeria spp. in raw and heat treated ready to eat dairy products. Commonwealth Vet. J. 30:4-8.

Urshev, Z., K. Hajo, L. Lenoci, P. A. Bron, A. Dijkstra, W. Alkema, M. Wels, R. J. Siezen, S. Minkova, and S. A. F. T. van Hijum. 2016. Draft genome sequence of Lactobacillus delbrueckii ssp. bulgaricus LBB.B5. Genome Announc. 4:e01090-16.

Van Brandt, L., K. Coudijzer, L. Herman, C. Michiels, M. Hendrickx, and G. Vlaemynck. 2011. Survival of Mycobacterium avium ssp. paratuberculosis in yoghurt and in commercial fermented milk products containing probiotic cultures. J. Appl. Microbiol. 110:1252-1261

van de Guchte, M., S. Penaud, C. Grimaldi, V. Barbe, K. Bryson, P. Nicolas, C. Robert, S. Oztas, S. Mangenot, A. Couloux, V. Loux, R. Dervyn, R. Bossy, A. Bolotin, J.-M. Batto, T. Walunas, J.-F. Gibrat, P. Bessières, J. Weissenbach, S. D. Ehrlich, and E. Maguin. 2006. The complete genome sequence of Lactobacillus bulgaricus reveals extensive and ongoing reductive evolution. Proc. Natl. Acad. Sci. USA 103:9274-9279.
Van Slyke, L. L., and E. B. Hart. 1904. Chemical changes in the souring of milk and their relations to cottage cheese. Bulletin 245. New York Agricultural Experiment Station, Geneva.

Vendramin, V., L. Treu, S. Campanaro, A. Lombardi, V. Corich, and A. Giacomini. 2017. Genome comparison and physiological characterization of eight Streptococcus thermophilus strains isolated from Italian dairy products. Food Microbiol. 63:47-57.

Volpe, R., L. Niittynen, R. Korpela, C. Sirtori, A. Bucci, N. Fraone, and F. Pazzucconi. 2001. Effects of yoghurt enriched with plant sterols on serum lipids in patients with moderate hypercholesterolaemia. Br. J. Nutr. 86:233-239.

Walstra, P., J. T. M. Wouters, and T. J. Geurts. 2006. Dairy Science and Technology. 2nd ed. CRC/Taylor \& Francis, Boca Raton, FL.

Wang, J. J., and J. F. Frank. 1981. Characterization of psychrotrophic bacterial contamination in comercial buttermilk. J. Dairy Sci. 64:2154-2160.

Weiss, N., U. Schillinger, and O. Kandler. 1983. Lactobacillus lactis, Lactobacillus leichmannii and Lactobacillus bulgaricus, subjective synonyms of Lactobacillus delbrueckii, and description of Lactobacillus delbrueckii ssp. lactis comb. nov, and Lactobacillus delbrueckii ssp. bulgaricus comb. nov. Syst. Appl. Microbiol. 4:552-557.

Werkman, C. H., and B. W. Hammer, inventors. 1940. Production of diacetyl in butter cultures. Iowa State College Research Foundation, assignee. US Pat. No. 2,196,239.

White, B. J., and T. J. Hill. 1949. Antagonistic relationship between oral organisms. J. Dent. Res. 28:272-275.

Wigley, R. C. 1977. The use of commercially available concentrated starters. Paper (a). J. Soc. Dairy Technol. 30:45-47.

Wijendra, W. A. S., K. A. K. C. Kulathunga, and R. Ramesh. 2014. First report of Listeria monocytogenes serotypes detected from milk and milk products in Sri Lanka. Adv. Anim. Vet. Sci. 2(S5):11-16.

Winkler, G. inventor. 1929. Process for the preparation of a mild aromatic yoghurt curdled milk or a sweet yoghurt junket. Alfred Zierer, assignee. US Pat. No. 1,710,133.

Yadav, H., S. Jain, and P. R. Sinha. 2007. Antidiabetic effect of probiotic dahi containing Lactobacillus acidophilus and Lactobacillus casei in high fructose fed rats. Nutrition 23:62-68.

Zourari, A., J. P. Accolas, and M. J. Desmazeaud. 1992. Metabolism and biochemical characteristics of yogurt bacteria. A review. Lait $72: 1-34$. 


\section{APPENDIX}

Table A1. Timeline of significant advances in the science and technology of yogurt and other cultured dairy products

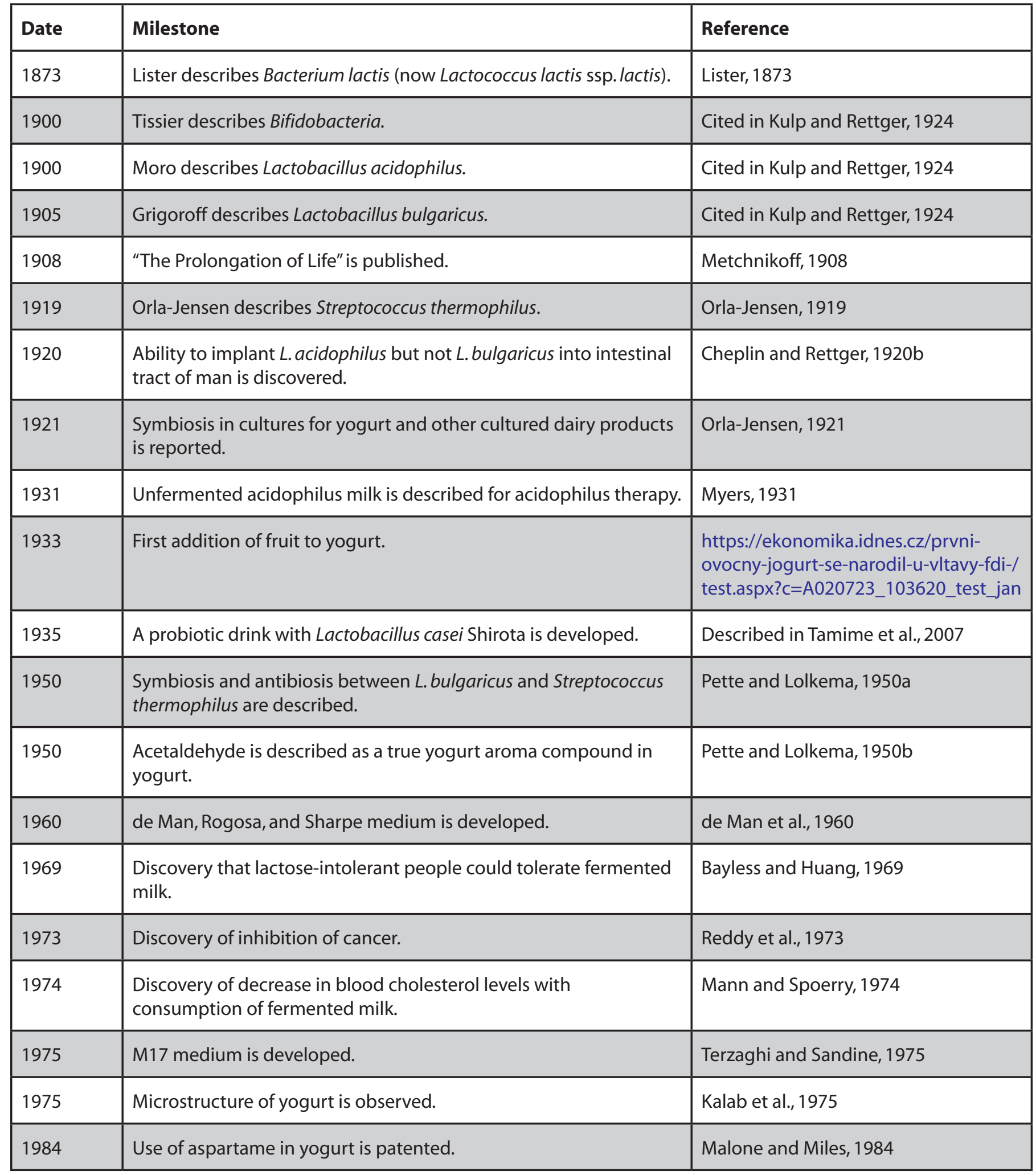


Table A1 (Continued). Timeline of significant advances in the science and technology of yogurt and other cultured dairy products

\begin{tabular}{|c|c|c|}
\hline Date & Milestone & Reference \\
\hline 1987 & $\begin{array}{l}\text { Yogurt containing Bifidobacterium animalis DN } 173010 \text { is } \\
\text { launched. }\end{array}$ & $\begin{array}{l}\text { https://www.activia.ca/en-us/explore- } \\
\text { science/history-activia }\end{array}$ \\
\hline 1988 & Genetic transformation of S. thermophilus by electroporation. & Somkuti and Steinberg, 1988 \\
\hline 1989 & Patent awarded for Lactobacillus rhamnosus GG. & Gorbach and Goldin, 1989 \\
\hline 1989 & Method for making fiber-enriched yogurt is patented. & Reddy, 1989 \\
\hline 1994 & Yogurt drink containing L. casei DN-114001 is launched. & $\begin{array}{l}\text { https://www.actimel.co.uk/the-story- } \\
\text { so-far }\end{array}$ \\
\hline 1995 & Inulin is first added to yogurt. & Robinson, 1995 \\
\hline 2004 & Genomic sequence of S. thermophilus is reported. & Bolotin et al, 2004 \\
\hline 2006 & Genomic sequence of L. bulgaricus is reported. & van de Guchte et al., 2006 \\
\hline 2008 & $\begin{array}{l}\text { Identification of S. thermophilus and L. bulgaricus using methionine } \\
\text { biosynthesis and } 16 \mathrm{~S} \text { rRNA. }\end{array}$ & Cebeci and Gūrakan, 2008 \\
\hline 2010 & Site-directed mutagenesis of S. thermophilus. & Blomqvist et al., 2010 \\
\hline 2014 & A low-galactose yogurt is developed. & Anbukkarasi et al., 2014 \\
\hline
\end{tabular}

